\title{
Distribución espacial de las clases altas en la región metropolitana de Madrid 2001-2011 ${ }^{1}$
}

\author{
Miguel Rubiales PÉREZ \\ Departamento de Geografía Humana \\ Universidad de Barcelona \\ mrubiale@gmail.com \\ Jordi BAYONA I CARRASCO \\ Departamento de Geografía Humana \\ Universidad de Barcelona \\ jordibayona@ub.edu \\ Isabel PUJADAS RÚBIES \\ Departamento de Geografía Humana \\ Universidad de Barcelona \\ iujadas@ub.edu
}

Recibido: 23 de octubre de 2013

Enviado a evaluar: 22 de marzo de 2013

Aceptado: 8 de julio de 2013

\section{RESUMEN}

La articulación espacial de elites y clases altas influye en el desarrollo urbano, puede condicionar la viabilidad de los servicios municipales y desencadenar polémicos procesos de gentrificación. Estos patrones de distribución territorial de las clases altas se estudian para la región metropolitana de Madrid mediante tres perspectivas: del análisis multivariable y cartográfico; de la intensidad de la segregación; y de la articulación interna que genera la movilidad obligada entre municipios. Los resultados indican que la CAM presenta cinco grandes conglomerados de municipios especializados socioespacialmente: tres de clase alta y medio-alta situados al norte y oeste de la comunidad, uno de carácter mixto al este (el subsistema entorno a Alcalá de Henares) y uno de clases bajas en el sur. Los datos a nivel de secciones censales muestran una fuerte segregación y un patrón característico de la CAM: centros urbanos con alta presencia de clases bajas. Esta configuración puede asociarse a la histórica preponderancia de Madrid capital.

Palabras clave: Segregación residencial, Región Metropolitana de Madrid; clases socioespaciales; gentrificación, movilidad obligada.

\footnotetext{
${ }^{1}$ Este trabajo forma parte del proyecto de I+D "Las nuevas ciudades españolas. El impacto espacial de las dinámicas demográficas recientes en las grandes áreas urbanas españolas en un contexto de crisis" (CSO2011-24680), dirigido por Isabel Pujadas. Los investigadores forman parte del grupo de investigación consolidado Población, Territorio y Ciudadanía, reconocido por la Generalitat de Cataluña (2009SGR01086) y dirigido por la Dra. Isabel Pujadas.
} 


\title{
Spatial distribution of the upper classes in the metropolitan area of Madrid 2001-2011
}

\begin{abstract}
The territorial patterns of high classes could affect urban development, the management of municipal services and the unleashing of gentrification processes. The spatial patterns and links of socio-economic groups in the urban area of Madrid (CAM) are examinated by combining three perspectives: the multivariate analysis, the intensity level of residential segregation, and the clustering of municipalities based on the population's obligatory mobility. The results indicate that the CAM has five major clusters of territorial specialization: three upper and upper-middle classes to the north and west of Madrid, one mixed to the east, which is the subsystem around Alcalá de Henares, and a lower class cluster in the south. The census track's data show a strong level of segregation for upper and lower classes and a characteristically abundance of downtowns populated by lower classes. This configuration can be associated to the traditional dominance of Madrid and the monocentrism of the whole region.
\end{abstract}

Key words: Residential segregation, Metropolitan Region of Madrid, Socio-spatial Classes, Gentrification, Urban Mobility.

\section{La distribution spatiale des classes supérieures dans la zone métropolitaine de Madrid 2001-2011}

\section{RÉSUMÉ}

La distribution spatiale des classes hautes peut influer sur le développement urbain, la gestion des services municipaux et l'apparition des processus de gentrification. On étude l'articulation des groupes socio-économiques dans la région métropolitaine de Madrid en combinant trois perspectives: l'analyse multivariable et sa représentation cartographique, l'intensité de la ségrégation spatiale et enfin les regroupements fonctionnels des municipalités par rapport aux déplacements quotidien de la population. Les résultats indiquent que la CAM a cinq noyaux principaux de spécialisation territoriale: trois noyaux de classes hautes situées au nord et à l'ouest de la communauté, un de type mixte a l'est (le sous-système situé autour d'Alcalá de Henares) et un groupe des municipalités ouvrières au sud. Les données inframunicipales témoignent d'une forte ségrégation des classes supérieures et inférieures et mettent en évidence l'un des traits caractéristiques de la CAM: l'abondance de centres urbaines avec une forte spécialisation des classes défavorisées. Cette abondance peut être liée au monocentrisme de la région métropolitaine de Madrid.

Mots clés: Ségrégation résidentielle, région métropolitaine de Madrid, classes socio-spatiales, gentrification, mobilité urbaine.

\section{INTRODUCCIÓN}

Los patrones de distribución espacial de las clases altas en la Comunidad Autónoma de Madrid, se analizan a partir de los datos del Censo de 2001 y de los registros de la seguridad social en 2007 y 2011. Para ello, se presta atención a cuatro dimensiones complementarias: 1) la distribución a nivel inframunicipal según nivel socioeconómico, 2) especialmente en relación con los centros urbanos y las periferias dispersas; 3) la intensidad de la segregación respecto de los demás grupos sociales; 4) la especialización socioeconómica de grupos de municipios y el nivel de vinculación funcional interna de éstos grupos. 
La tendencia hacia la diferenciación espacial que muestran los grupos con mayor nivel adquisitivo no suele entenderse como problemática. Sin embargo, las dinámicas que encarnan esta tendencia general: congregación, retirada y elitización plantean directa, o indirectamente cuestiones políticas y sociales que afectan a la convivencia, la sostenibilidad y la viabilidad de servicios municipales (Atkinson, 2004).

La elitización (García Herrera, 2007) o gentrificación (Lees, 2011) se ha problematizado de forma más frecuente a causa de la conflictividad, en ocasiones abierta, que supone el desplazamiento de la población anterior. Aquí, el derecho a la ciudad (Harvey, 2008) de la población con menos recursos choca con las necesidades de distinción de los más pudientes y con dinámicas de la generación de plusvalías urbanas.

Por otro lado, la retirada de las clases altas hacia municipios especializados de la región metropolitana se encuentra relacionada con la proliferación de urbanizaciones de baja densidad, la multiplicación de las infraestructuras viarias, mayor uso del vehículo privado... en cierta forma, sería posible rastrear como esta retirada que practicaban las clases altas durante los años setenta pudo utilizarse por agentes promotores e inmobiliarios como referente de un estilo de vida a imitar (Bourdieu, 2001), consiguiendo su generalización (Pujadas, 2005) en un modelo urbano que repercute en el funcionamiento justo y eficiente del "resto" de la ciudad. Hortas y Solé (2008) han encontrado evidencias empíricas de que los recientes desarrollos urbanos de baja densidad incrementan el coste de provisión de los servicios públicos locales. Además de su impacto directo sobre los servicios municipales, la generación de espacios segregados de residencia, trabajo, estudio, movilidad y recreo incrementa la vulnerabilidad política de los espacios y servicios públicos porque los miembros de la comunidad con más capacidad para defenderlos dejan de estar directamente interesados en su mantenimiento. Esto puede concretarse desde en la degradación de un parque, el mal olor del alcantarillado, hasta en las dificultades de viabilidad del transporte público o pérdidas de calidad en la atención primaria...

Otro motivo de preocupación sería que los procesos de separación de las clases altas parecen estar creciendo en intensidad, nuevas tipologías (como las comunidades cerradas) y extensión. Frecuentemente se sugiere que el desarrollo tecnológico, la mundialización económica y las políticas que, hasta ahora, la acompañan, están relacionadas con el incremento del tamaño de las metrópolis y de su segregación interna (Soja, 2000). Graham y Marvin (2001) relacionan el desarrollo de la metrópolis postmoderna con la creación de auténticas islas sociales dentro del tejido urbano. Los intentos de establecer cuáles son las repercusiones socioterritoriales, las externalidades negativas y los mecanismos de los crecientes procesos de separación entre clases deben partir de un diagnóstico lo más preciso posible sobre su distribución espacial. Éste es precisamente el objetivo, aplicado a la Región Metropolitana de Madrid, de nuestro artículo: tras 2) unas consideraciones conceptuales y 3) metodológicas, se da cuenta del 4) stock de las diferentes categorías profesionales, de 5) las principales características de la articulación socio espacial y se ofrece una serie de 6) representaciones cartográficas detalladas tanto de los grandes grupos municipales, 
como de su composición interna. Finalmente, también se analiza 7) la articulación funcional interna de los grupos de municipios a partir de la movilidad obligada que comparten.

\section{CONGREGACIÓN Y SECLUSIÓN}

Proponemos generar dos nuevos términos asignando sentidos diferentes a los conceptos de congregación (Marcuse, 1997) y retiro o seclusión (Atkinson, 2004). El término congregación es acuñado en los ochenta por Van Amersfoort et al. (1987) y Marcuse (1997) lo recupera para describir el proceso de separación voluntaria de las poblaciones con más recursos, equivalente de las dinámicas de white flight descritas por los estudios aplicados de segregación étnica en Estados Unidos. Atkinson y Flint (2004) emplean para el mismo concepto, otro término: seclusion. Definen seclusion como el movimiento de retirada y agrupación voluntaria de los estratos superiores de la población.

Ambos términos, congregación y seclusion, tienen una etimología similar: indican la formación de un endogrupo y la diferenciación del resto por motivos, entre otros, religiosos. El término seclusion (cuya traducción libre al castellano sería retirada, en el sentido de retiro espiritual) incorporaba, en su primigenia acepción religiosa, connotaciones de separación, salida de la vida urbana y relativo aislamiento. Aunque ambos se generaron como sinónimos, su sentido académico actual podría adaptarse para diferenciar entre las dos estrategias fundamentales de la segregación voluntaria de las clases altas: el concepto de congregación haría referencia a la agrupación voluntaria en entornos urbanos densos, mientras que el patrón de seclusión o patrón de retirada del centro designaría el movimiento hacia municipios de la región metropolitana y / o hacia zonas suburbanas de baja densidad, alta dispersión y alta homogeneidad social. Así, la elitización sería un tipo de congregación en curso, un "proceso de transformación de determinados sectores de sus áreas centrales provocando su revitalización funcional y el cambio en la composición social de sus habitantes." (García Herrera, 2007).

\section{CONSIDERACIONES METODOLÓGICAS}

A falta de un área formal que administre la dinámica funcional de la ciudad de Madrid bajo la definición de una gran región metropolitana, es frecuente emplear la Comunidad Autónoma de Madrid (CAM) como ámbito metropolitano de referencia. La CAM incluye 178 municipios, con una extensión de $8.038 \mathrm{~km}^{2}$ y con $6.489 .680 \mathrm{de}$ habitantes en 2011. Ha sufrido un fuerte crecimiento de su población en la última década, que aumenta prácticamente un $20 \%$ desde los 5.423 .384 habitantes del año 2001. Paralelamente a este fuerte aumento poblacional, también se ha producido un intenso proceso de suburbanización y de desconcentración de la actividad económica. Así, Madrid ha pasado de representar el 67,4\% de la población de la CAM en 1981 al $50,3 \%$ actual (Pujadas y Bayona, en prensa). 
Algunas cuestiones previas al análisis, como la validez del criterio de agrupación, sus variables de operacionalización, la mecánica estadística de cálculos y la fiabilidad de los datos, resultan elementos relevantes para dar cuenta de forma solvente de las clases socio-espaciales en su articulación territorial.

La operativización del concepto de segregación requiere tanto la selección de un criterio de agrupación que sea explicativo, como la disponibilidad de datos válidos y fiables. Así, este artículo se apoya en una aproximación multivariable a la segregación por clases o grupos sociales, adaptada a la información del Censo de 2001, y en un criterio más básico, basado en la categoría profesional, para trabajar con los datos de la Seguridad Social de los años 2007 y 2011. Se incluye 2007, año de inicio de la primera fase de la crisis económica, para controlar si los grandes cambios del periodo de crecimiento $2001-2007$ no se veían oscurecidos por el "aterrizaje" que supone la primera fase de la crisis $(2007-2011)$.

La aproximación multivariable ${ }^{2}$ permite una caracterización detallada de la segregación y tener en cuenta, además de la categoría profesional, variables como el nivel de estudios, la nacionalidad, la incidencia del desempleo y el tamaño de la vivienda (ver anexo 1 para la lista completa de variables utilizadas). Esta combinación de variables mantiene la centralidad del criterio socioeconómico (construido sobre la categoría profesional) pero también incluye criterios sobre los que operan otros procesos de segregación. Esta orientación multicriterio comienza también a emplearse en estudios sobre segregación étnica, que abogan por la integración de consideraciones de clase de cara al análisis de la segregación según nacionalidades (Malheiros 2002 o Waquand 2007).

El análisis multivariable consiste en un análisis factorial y, a partir de sus resultados, uno de conglomerados. El análisis factorial reduce las variables a unos pocos factores eliminando redundancias y estandarizando los valores resultantes; después, el análisis de conglomerados tiene en cuenta los valores generados por el análisis factorial para asignar las secciones censales a grandes grupos según el parecido de sus valores. El principal problema de esta técnica deriva de la falta de disponibilidad actualizada de todos los datos.

\footnotetext{
${ }^{2}$ Factorial de componentes principales, con método de rotación Varimax y análisis de conglomerados jerárquicos mediante el método de Ward (sobre la distancia euclídea).
} 
Tabla 1. Agrupación de las ocupaciones en grandes categorías.

\begin{tabular}{|c|c|c|}
\hline $\begin{array}{c}\text { Censo 2001, Clasificación } \\
\text { de las profesiones, CNO } \\
1994\end{array}$ & $\begin{array}{l}\text { Seguridad Social, clasificación } \\
\text { según grupos de cotización }\end{array}$ & $\begin{array}{l}\text { Agrupación por } \\
\text { categorías }\end{array}$ \\
\hline 1.Personal directivo & Ingenieros y Licenciados & \multirow{2}{*}{$\begin{array}{l}\text { Categoría alta } \\
\text { Nivel } 3 \text { Seg. Soc. }\end{array}$} \\
\hline $\begin{array}{l}\text { 2.Técnicos y profesionales } \\
\text { científicos e intelectuales }\end{array}$ & $\begin{array}{c}\text { Ingenieros Técnicos, Peritos y } \\
\text { Ayudantes Titulados }\end{array}$ & \\
\hline \multirow{3}{*}{$\begin{array}{c}\text { 3.Técnicos y profesionales de } \\
\text { apoyo }\end{array}$} & Jefes Administrativos y de Taller & \multirow{3}{*}{$\begin{array}{l}\text { Categoría } \\
\text { media-alta }\end{array}$} \\
\hline & Ayudantes no titulados & \\
\hline & Oficiales Administrativos & \\
\hline \multirow{2}{*}{$\begin{array}{l}\text { 4.Empleados de tipo adminis- } \\
\text { trativo }\end{array}$} & Subalternos & \multirow{2}{*}{ Nivel 2 Seg. Soc. } \\
\hline & Auxiliares Administrativos & \\
\hline $\begin{array}{c}\text { 5.Trabajadores de los servi- } \\
\text { cios y vendedores de comer- } \\
\text { cio }\end{array}$ & \multirow{3}{*}{$\begin{array}{l}\text { Oficiales de primera } \\
\text { y de segunda }\end{array}$} & \multirow{5}{*}{$\begin{array}{c}\text { Categoría } \\
\text { media-baja } \\
\text { Nivel } 1 \text { Seg. Soc }\end{array}$} \\
\hline $\begin{array}{c}\text { 6.Trabajadores en actividades } \\
\text { agrarias y pesqueras }\end{array}$ & & \\
\hline $\begin{array}{l}\text { 7.Trabajadores cualif. de la } \\
\text { indust., construc. y miner }\end{array}$ & & \\
\hline $\begin{array}{c}\text { 8.Operadores de instalacio- } \\
\text { nes y conductores }\end{array}$ & \multirow{2}{*}{$\begin{array}{l}\text { Oficiales de tercera } \\
\text { y Especialistas }\end{array}$} & \\
\hline 10.Fuerzas armadas & & \\
\hline \multirow{2}{*}{ 9.Trabajadores sin cualificar } & Peones & \multirow{2}{*}{$\begin{array}{l}\text { Categoría baja } \\
\text { Nivel } 1 \text { Seg. Soc. }\end{array}$} \\
\hline & Trabajadores menores de 18 años & \\
\hline
\end{tabular}

Fuente: Elaboración propia a partir de Pujadas y García Coll (2005).

La actualización de los datos del censo 2001 se realiza, a nivel municipal, empleando datos de los trabajadores registrados en el Régimen General que permiten agrupar conglomerados socioespaciales de municipios a partir de perfiles homogéneos (ver figura 4). Se representan calculando coeficientes de localización de los grupos de mayor cotización agrupándolos a partir de intervalos creados mediante el método de Jenks. Esta manera de agrupar, supone una versión simplificada (y adaptada a los datos disponibles) de la representación de conglomerados construidos a partir de un análisis factorial que se aplica a los datos censales en el análisis inframunicipal 
de este artículo ${ }^{3}$. La elección de caracterizar lo municipios en relación a los cocientes de localización (LQ) para la población en ocupaciones altas del Censo de 2001 (Personal directivo; Técnicos y profesionales científicos e intelectuales) y para los grupos de mayor cotización de la Seguridad Social (Ingenieros y Licenciados; Ingenieros Técnicos, Peritos y Ayudantes Titulados) en 2007 y 2011 responde a tres motivos: la efectividad de la operacionalización del carácter de clase de un territorio a partir de la presencia de población de clase alta, el estudio de fiabilidad del censo y la universalidad de ambas fuentes de datos.

La efectividad del porcentaje de población de clase alta como indicador queda contrastada por los análisis similares en la Región Metropolitana de Barcelona, que señalan una correlación del 0,97 respecto a la población con estudios de tercer ciclo (Rubiales et al. en prensa) y con la ausencia de clases bajas (correlaciones de $-0,94 \mathrm{y}-$ 0,72 con población ocupadas en categorías medio bajas y bajas, respectivamente). También se encuentra muy relacionada con la renta (Moreno, 2003). Desde un punto de vista teórico, los patrones de congregación dentro del propio grupo y de distinción hacia los demás hacen que el porcentaje de trabajadores en categorías altas sirva tanto para indicar el carácter alto como el bajo de cualquier unidad territorial, municipio o sección censal. Finalmente, la población en ocupaciones directivas, técnicas y científicas se representa con menos errores en censos y registros porque es un grupo construido, generalmente, en base a acreditaciones laborales y educativas, que está normalizado y que es objeto de deseabilidad social. Así su porcentaje es un buen indicador de la presencia de elites y de su ausencia relativa, indicador de zonas mixtas o, incluso, de poblaciones en riesgo de exclusión.

Los estudios de fiabilidad del censo (INE, 2007) sobre las variables más utilizadas comparan sus datos con las respuestas en la Encuesta de Población Activa (EPA), vivienda a vivienda ${ }^{4}$. En sus resultados aparecen deslizamientos, mayoritariamente, entre las categorías ocupacionales vecinas. La agrupación de las categorías profesionales en alta, medio alta, medio baja y baja limita gran parte de estos problemas de deslizamiento. Finalmente, la universalidad de ambas fuentes de datos resulta clave para permitir su yuxtaposición. La principal diferencia entre las fuentes sería la deri-

\footnotetext{
${ }^{3}$ El Cociente de localización indica la proporción de población en la unidad espacial en relación a la proporción del conjunto del territorio: $\mathrm{LQ}=(\mathrm{x} / \mathrm{n}) /(\mathrm{X} / \mathrm{N})$. La agrupación de Jenks calcula intervalos que minimicen las diferencias internas y maximicen las diferencias entre intervalos en función de una sola variable. Sería el equivalente univariable a la agrupación por conglomerados. Para los datos de los tres periodos, la agrupación de Jenks arrojaba valores muy similares, de los que se ha establecido la media como agrupación común para comparar los datos.

${ }^{4}$ Contrastan los resultados del Censo con los de la EPA, considerados fiables por su gran muestra (más de 74.000 familias en 2001), mecánica de panel que permite familiaridad con el cuestionario y corrección de errores. El informe ofrece dos tipos de tablas: las referidas a errores de contenido y las de indicadores de calidad y concluye que para las agrupaciones aquí realizadas (primer ciclo, segundo ciclo... ocupaciones altas, medio altas...), los datos son fiables.
} 
vada del trabajo irregular y de los fallos de registro (ambos menores en las categorías laborales altas).

Los índices de segregación resultan un complemento adecuado a la caracterización espacial y cartográfica. Ofrecen una medida de resumen de la separación, cuán intensa o efectivamente se ha traducido en distancia. En este artículo se emplean dos de los más sencillos: el índice de segregación general y los de de disimilitud bigrupo ${ }^{5}$. A pesar de su progresiva sofisticación matemática, la información que proporcionan es similar: medida de resumen del nivel de concentración de los diferentes grupos en las unidades espaciales estudiadas. Así, los resultados variarán no sólo en función de cómo se definan los grupos y el tamaño de las unidades espaciales, sino también en relación de la propia definición de área metropolitana, sus límites y su morfología singular. Por esto, las comparaciones basadas exclusivamente en estas medidas de resumen son metodológicamente problemáticas y se utilizan, principalmente, como orientación general.

El estudio de la movilidad obligada intermunicipal que se realiza al final, emplea el análisis de redes sociales con una doble función: por un lado, permite verificar la pertinencia de las agrupaciones socioespaciales de municipios a partir de datos empíricos sobre procesos reales de interconexión (más allá de su proximidad geográfica o su similitud socioeconómica); por otro lado, muestra si la segregación en la región de Madrid, además de residencial, podría darse también en la localización de los puestos de trabajo.

El carácter complementario que aporta el análisis de la movilidad obligada en este artículo hace preferible centrarlo en la visualización de los resultados. No se calculan índices de autorretención, dispersión y dependencia, que han sido tratados recientemente por otros autores (Río, 2009). Se aplica el algoritmo Forceatlas2 (Jacomi et al., 2011), una modificación del algoritmo del tipo basado en fuerzas (Fruchterman y Reingold, 1991) en el que los nodos se repelen como partículas con la misma carga magnética y se atraen en función del peso de la(s) arista(s) que los conectan. Partiendo de una distribución aleatoria, municipios más conectados de manera más intensa aparecen situados más próximos. Se ha representado esta red de desplazamientos entre municipios en función del porcentaje de trabajadores que se mueven de uno a otro para aquellos desplazamientos pertenecientes a la CAM, mayores del $0,5 \%$, desde y hacia municipios de más de 2.000 trabajadores inscritos en el régimen general

${ }^{5}$ El índice de segregación calcula la diferencia entre la proporción de individuos un grupo y la proporción del de todos los demás grupos en unidad administrativa. Se define como:

IS $=\frac{1}{2} \sum_{i=1}^{n}\left|\frac{x_{i}}{X}-\frac{t_{i}-x_{i}}{T-X}\right| \quad 0 \leq I S \leq 1$

El índice de disimilitud (bigrupo) es muy parecido al de segregación, pero compara la proporción de un grupo con la de otro, no con el total. Se define como:

$\mathrm{D}=\frac{1}{2} \sum_{\mathrm{i}=\mathrm{i}}^{\mathrm{a}}\left|\frac{\mathrm{x}_{\mathrm{i}}}{\mathrm{X}}-\frac{\mathrm{y}_{\mathrm{i}}}{\mathrm{Y}}\right| \quad 0 \leq \mathrm{D} \leq 1$ 
de la seguridad social. Para poder visualizar los subcentros y agrupaciones dentro de la CAM, también se ha excluido Madrid, cuyo gran peso tiende a ocultar las demás interacciones.

\section{CLASES SOCIALES Y CATEGORÍAS PROFESIONALES EN LA CAM}

Los registros de la Seguridad Social son una fuente fiable de la que el instituto de estadística de la Comunidad de Madrid ofrece una gran selección de variables y cruces. Estos datos se han comenzado a utilizar en investigaciones sobre diversos temas, como la distribución territorial de las actividades económicas, (García Palomares, 2008; Río, 2009; Méndez, 2011) y abren la posibilidad, explorada en este artículo, de actualizar la estratificación clasista del territorio metropolitano.

Los registros de la seguridad social (ver tabla 1) muestran, a grandes rasgos, la configuración socioeconómica de la CAM y los volúmenes de población a los que se hace referencia al hablar de clases en la CAM. Entre 2.805.748 afiliados, la CAM aglutina algo más de 527.000 directivos y profesionales científicos (un 19\% del total de registrados), lo que supone el mayor volumen de clases altas y medias de España. El otro $80 \%$ se reparte entre un $39 \%$ en grupos de cotización de nivel 2 (algo más de 1.100 .000 trabajadores), un $26 \%$ para el nivel uno (739.000 oficiales y peones) y un $3 \%(72.000)$ dedicado a tareas domésticas. El 13\% relativo al régimen de autónomos resulta difícil de interpretar desde una lógica clasista porque cuenta con una altísima heterogeneidad interna, mayor incluso que en las demás categorías.

Figura 1. Evolución de la población registrada en la Seguridad Social por régimen y grupo de cotización, CAM 2007-2011.

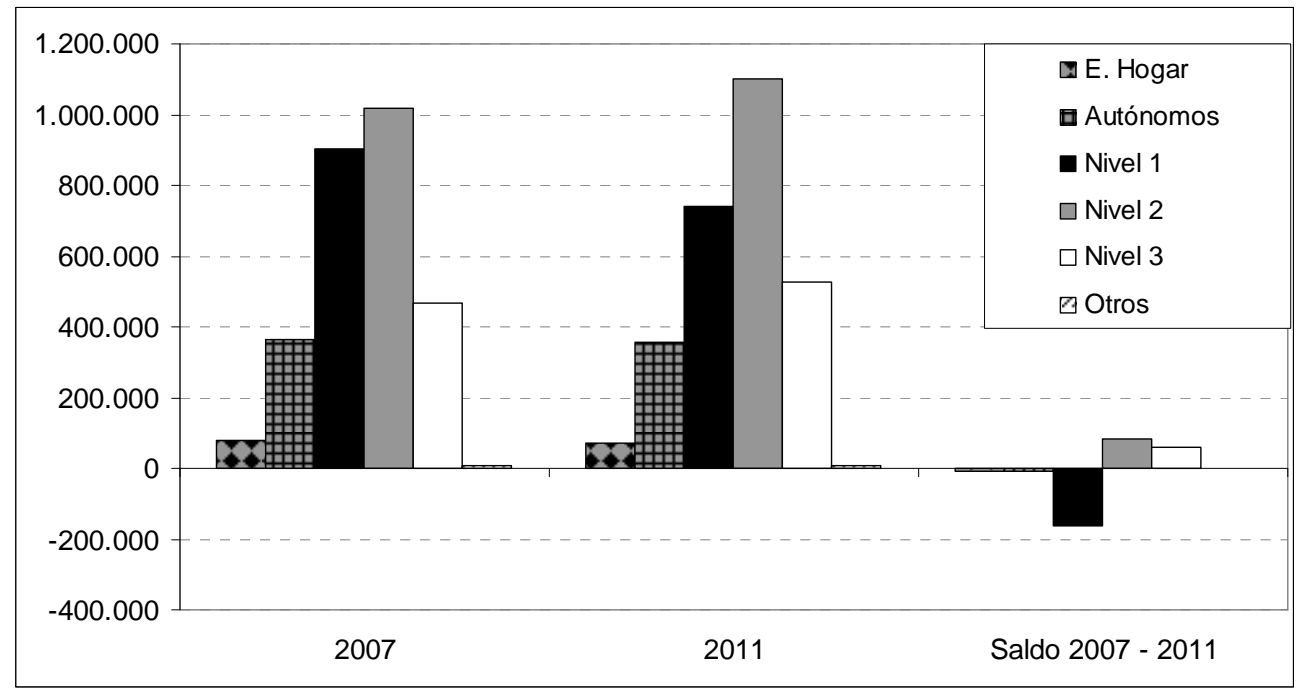

Fuente: Instituto de Estadística de la Comunidad de Madrid (IECM). Elaboración propia. 
Una primera distribución territorial de las diferentes categorías profesionales en la región muestra, no sólo la especialización de la ciudad central (Madrid) en las categorías y funciones superiores (nivel 3 de las figuras 1 y 2 ), sino también que el proceso de desconcentración laboral hacia la periferia se ha mantenido, también, durante la primera fase de la crisis (periodo 2007-2011). Las ocupaciones en grupos más bajos de cotización descienden más proporcionalmente en Madrid (74.718 registrados menos, un $20 \%$ respecto al volumen inicial) que en el resto (87.607 menos, un $16 \%$ ) y los crecimientos de los registrados en los niveles 2 y 3 crecen sólo un $4 \%$ y un $10 \%$ respectivamente en Madrid, mientras que en el resto de la CAM los aumentos son del $12 \%$ y $17 \%$, respectivamente.

Figura 2. Registrados en la seguridad social según grupo de cotización y localización territorial, CAM 2007-2011

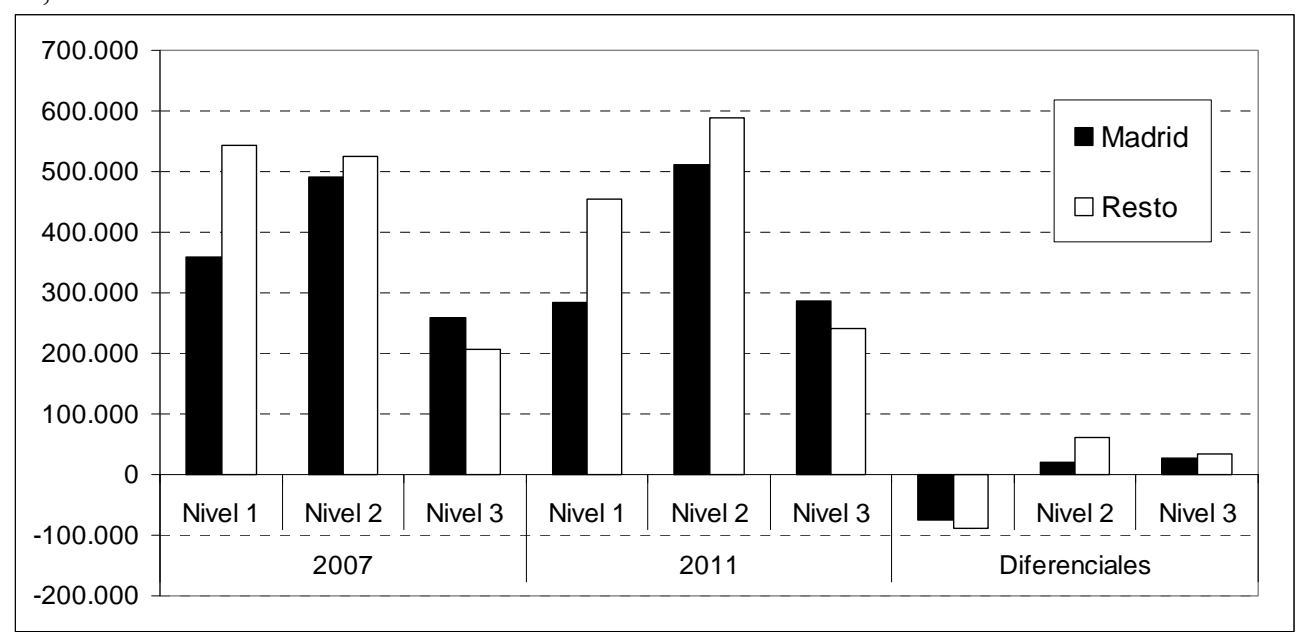

Fuente: Instituto de estadística de la Comunidad de Madrid (IECM). Elaboración propia.

\section{PRINCIPALES CARACTERÍSTICAS DE LA ARTICULACIÓN SOCIOESPACIAL DE la CAM}

Desde el punto de vista de la distribución clasista y los perfiles socioeconómicos de su población, la CAM es una región polarizada, segregada, estable, con marcados contrastes inframunicipales entre núcleos urbanos densos y periferias dispersas, en la existe una especialización social mediante bloques supramunicipales homogéneos y referidos a la ciudad de cabecera. Los grandes tipos socioespaciales que componen la CAM son: el grupo de municipios de elite, el residencial suburbano, el de municipios medios y mixtos (como el subsistema formado por los municipios del corredor del Henares), el trabajador o de clases bajas y el de los pequeños municipios alejados. Más adelante se analizan en detalle. 
Los índices de segregación (ver tabla 3) muestran un resumen numérico de la polarización y separación de las clases altas en la CAM, que también puede apreciarse gráficamente (ver figuras de la 6 a la 11, o tabla 2 y anexo 2, para ver la tabla completa). Así, los conglomerados que caracterizan las secciones censales en función de su carácter de clase alta, media y clase baja presentan fuertes contrastes en sus valores medios. Las secciones censales altas y medias albergan, respectivamente, porcentajes del $76,4 \%$ y el $57,7 \%$ de población en las ocupaciones superiores, mientras que las secciones de clase más baja ofrecen la imagen complementaria: entre un 55,6\% y un $70,7 \%$ en ocupaciones medio bajas (trabajadores y operarios) y bajas (empleos sin cualificación).

Tabla 2. Resumen conglomerados y valores medios de las variables

\begin{tabular}{|c|c|c|c|c|c|}
\hline Variables & $\begin{array}{c}\text { Clase } \\
\text { alta }\end{array}$ & $\begin{array}{l}\text { Clase } \\
\text { media }\end{array}$ & $\begin{array}{l}\text { Clase medio } \\
\text { baja dispersa }\end{array}$ & $\begin{array}{c}\text { Clase } \\
\text { baja }\end{array}$ & $\begin{array}{c}\text { Clase baja } \\
\text { dispersa }\end{array}$ \\
\hline \multicolumn{6}{|l|}{ Leyenda en los mapas } \\
\hline Número de sec. censales & 867 & 1.019 & 496 & 1.162 & 362 \\
\hline \% alta ocupación & 49,1 & 25,6 & 16,7 & 13,3 & 10,2 \\
\hline \% medio alta ocupación & 27,3 & 32,1 & 26,6 & 24,1 & 18,5 \\
\hline \% medio baja ocupación & 15,9 & 31,2 & 44,5 & 45,0 & 55,2 \\
\hline \% baja ocupación & 6,7 & 10,3 & 11,1 & 17,0 & 15,5 \\
\hline$\%$ viviendas menos $75 \mathrm{~m}^{2}$ & 22,3 & 53,1 & 24,1 & 78,0 & 26,8 \\
\hline$\%$ viviendas de 75 a $120 \mathrm{~m}^{2}$ & 44,9 & 42,5 & 65,5 & 20,4 & 63,6 \\
\hline \% de viviendas mas $120 \mathrm{~m}^{2}$ & 32,7 & 4,4 & 10,5 & 1,6 & 9,6 \\
\hline \% población extranjera & 5,2 & 6,6 & 4,2 & 10,6 & 4,3 \\
\hline
\end{tabular}

Fuente: INE, Censo de 2001. Elaboración propia.

El tamaño medio de la vivienda es un indicador muy eficaz de las condiciones habitacionales, estilo y nivel de vida. Matiza la clasificación de las zonas de tradición rural en las que la categoría ocupacional no resulta tan determinante de la posición (y aún menos de la condición) de clase, al tiempo que refuerza las diferencias entre la clase alta $\left(77,6 \%\right.$ de viviendas de más de $\left.75 \mathrm{~m}^{2}\right)$, la media $(53 \%$ en viviendas de menos de $75 \mathrm{~m}^{2}$ ) y la baja $\left(78 \%\right.$ en viviendas de menos de $75 \mathrm{~m}^{2}$ ). Así, el conglomerado de clase baja dispersa caracteriza a las zonas de antigua tradición rural (con categorías ocupacionales bajas, pero mejores estándares habitacionales). Podría considerarse que estas zonas se encuentran poco integradas en las dinámicas de estructuración clasista de la metrópolis. Presentarían un sistema clasista propio o parcialmente solapado con las lógicas de clasificación general (tienen categorías ocupacionales más bajas, paro mantienen estilos de vida y acceso a estándares residenciales mejores -el 73,2\% de la población habita en viviendas de más de $75 \mathrm{~m}^{2-}$ ). 
Tabla 3. Índices de segregación en la CAM

\begin{tabular}{|c|c|c|c|c|c|c|}
\hline \multirow{2}{*}{ Variable } & \multirow{2}{*}{ Í. Segregación } & \multicolumn{4}{|c|}{ Índices de Disimilitud } \\
\cline { 3 - 7 } & & & Alta & Medio Alta & Medio Baja & Baja \\
\hline \multirow{3}{*}{$\begin{array}{c}\text { Secciones } \\
\text { Censales }\end{array}$} & Alta & 0,31 & & 0,26 & 0,45 & 0,42 \\
\cline { 2 - 7 } & Medio Alta & 0,17 & 0,26 & & 0,23 & 0,23 \\
\cline { 2 - 7 } & Med. Baja & 0,23 & 0,45 & 0,23 & & 0,14 \\
\cline { 2 - 7 } & Baja & 0,25 & 0,42 & 0,23 & 0,14 & \\
\hline
\end{tabular}

Fuente: INE, Censo de 2001, elaboración propia.

El conglomerado de clase medio baja dispersa está integrado en la dinámica metropolitana (espacial y cuantitativamente) pero más alejado de los núcleos más densificados. Con valores ocupacionales inferiores a los del conglomerado de clase media, sin embargo, su porcentaje de población en viviendas pequeñas se reduce a menos de la mitad (53,1\% para clase media $24,1 \%$ para medio baja dispersa). Su distribución en las cartografías de detalle muestra que se localiza en las zonas más abiertas de municipios con poblaciones relativamente grandes (ver figuras 8, 9 y 10).

Los índices de segregación muestran una región metropolitana en la que existe separación de las residencias en función de la clase social. Esto ocurre, especialmente en la población de clase alta, de las que una de cada tres viviendas se localiza siguiendo estrictos criterios de segregación. La proporción llega a una de cada dos personas si, además de directivos, licenciados, científicos y técnicos incluimos en este grupo al personal administrativo y a los técnicos y profesionales de apoyo. El nivel de segregación de la CAM es ligeramente mayor al observado en la Región Metropolitana de Barcelona. Ambas presentan el mismo valor en el índice de segregación, de 0,31 para la clase alta, pero en la CAM aparecen valores algo mayores para la clase baja y medio alta: de 0,25 frente a 0,20 y de 0,20 frente a 0,13 , respectivamente (Rubiales et al., en prensa). En las segregaciones entre grupos, las estructuras son parecidas, con una clase alta que se separa fuertemente de las medio bajas y bajas (ver tabla 3).

Figura 3. Comparativa de índices de segregación en diferentes ciudades y grupos

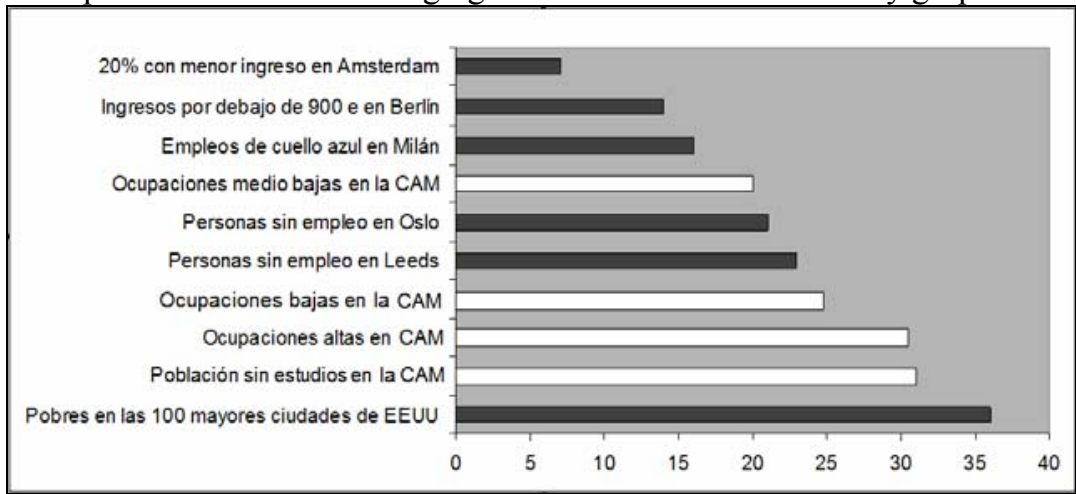

Fuente: Elaboración propia a partir de Musterd y Van Kempen (2005). 
Se debe tener en cuenta que no miden lo mismo índices de segregación iguales obtenidos en zonas diferentes. Cabe indicar, a modo de contextualización, que la segregación de las ocupaciones más altas en la CAM en relación a otras áreas y grupos sociales, sería comparable a la de la población sin estudios en la CAM y ligeramente menor a la segregación de los pobres en las 100 ciudades más pobladas de los Estados Unidos (0,31 frente a un 0,36 que se considera un nivel de segregación intenso). Además, el índice de segregación de las ocupaciones bajas en la CAM es mayor que el índice para grupos marginados de ciudades europeas equivalentes como los desempleados en ciudades inglesas o la población desempleada de Oslo (ver figura 3).

Figura 4. Concentración (LQ) de los grupos altos en la CAM, años 2001, 2007, 2011

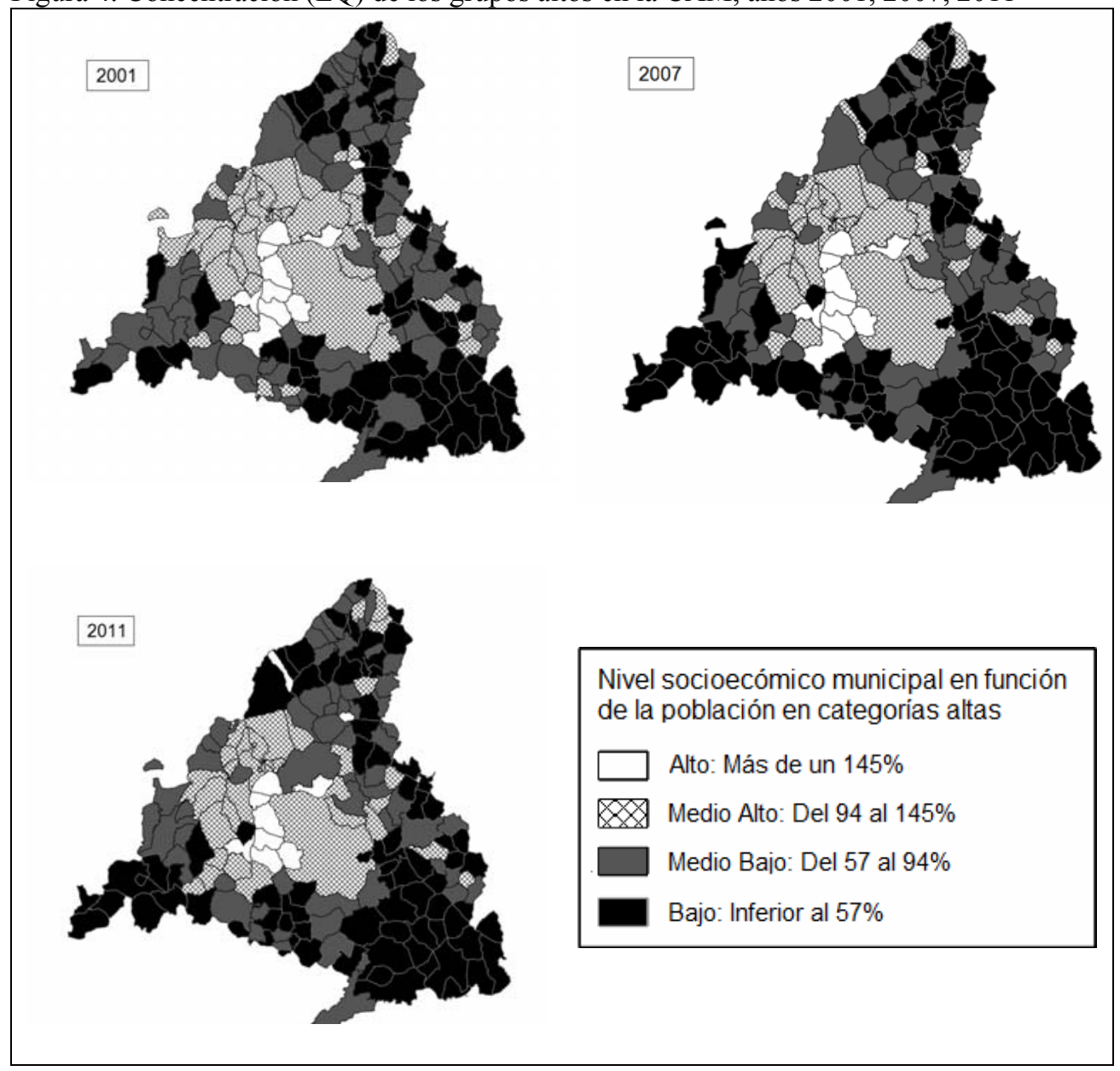

Fuente: INE e IECM, Censo de 2001, datos de afiliados a la Seguridad Social, 2007-2011. Elaboración propia. 
Las diferencias a nivel inframunicipal entre centros urbanos y periferia dispersa es otro de los rasgos de la segregación en la CAM que muestran los datos inframunicipales. En la Comunidad de Madrid predominan municipios en los que su carácter general coincide con el de su centro pero en los que existe un contraste con el carácter de sus zonas periurbanas. Dos procesos de migraciones internas dan lugar a esta configuración: en primer lugar, el desplazamiento del campo a la ciudad durante los $60 \mathrm{~s}$ y 70s que incorporó población con menores niveles de formación y empleo compactándola en el sur y este de Madrid; y la suburbanización residencial de las clases medias y altas que han ido saliendo de Madrid instalándose de manera más dispersa en los municipios de la Comunidad durante las últimas tres décadas. El contraste sociodemográfico depende de la localización y estado de desarrollo del municipio, en el momento de recibir estos flujos.

Figura 5. Agrupación de municipios en función de su población en categorías altas

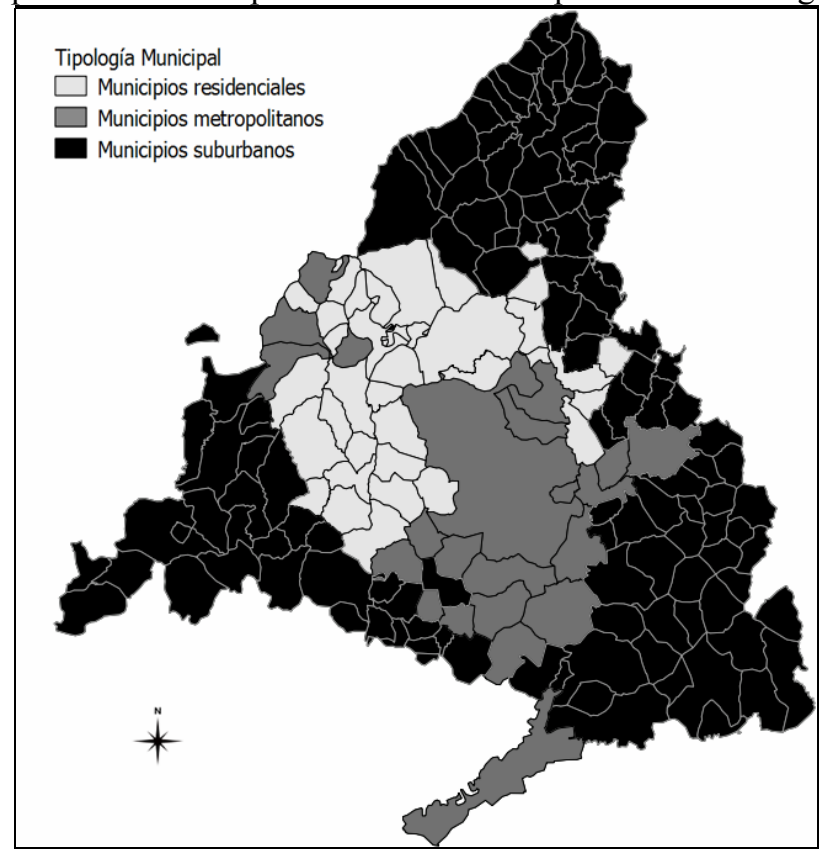

Fuente: INE e IECM, datos del Censo de 2001 y registros de la Seguridad Social, 2007 y 2011 y elaboración propia.

A pesar de los fuertes cambios que se han producido en la CAM durante el periodo 2001-2011, la caracterización socioeconómica de los territorios resulta bastante estable, especialmente si se estudian grandes unidades como los distritos de la capital o los municipios de su entorno (ver figura 4). Esta estabilidad se produce por dos motivos: la traslación de la estructura (Bourdieu, 1988) y la integración funcional del área estudiada. La traslación de la estructura consiste en la conservación de las 
posiciones relativas de clase aunque varíen las condiciones de vida. La integración funcional de la región hace que los cambios tiendan a producir efectos en el conjunto manteniendo las posiciones relativas de clase. La variabilidad que se produce en algunos municipios muy pequeños debe atenderse con precaución ya que ligeras variaciones o errores de medida respecto a municipios de pocos habitantes podrían producir saltos en la clasificación.

\section{LAS CLASES SOCIOESPACIALES EN LA CAM}

Una primera caracterización básica de la CAM a nivel municipal teniendo en cuenta múltiples variables del censo de 2001 (ver anexo 1) clasificaría los municipios en aquellos con un fuerte componente residencial y predominio de las clases altas, que se localizan rodeando la capital por la zona norte y oeste; los municipios mixtos de carácter metropolitano con importantes concentraciones de población trabajadora que se ocuparían las zonas sur y este respecto Madrid; y los municipios menos integrados en las estructuras clasistas y laborales de la metrópolis, bien por su distancia y escaso tamaño, bien por incluir los segmentos más desfavorecidos de la pirámide social. Este último grupo de municipios es el localizado a mayor distancia de Madrid, tanto en la Sierra Norte, la Sierra Oeste como el extremo este de la comarca de las Vegas. De características muy diferentes respecto a los grandes municipios de la CAM, no se encuentran integrados en las dinámicas residenciales de las clases altas.

Otras dificultades de la caracterización a nivel municipal derivan de la heterogeneidad municipal, resultante tanto de una composición poblacional variada, de su segregación a escala inframunicipal, o de su posible articulación en torno a diferentes núcleos poblacionales. Por este motivo, es conveniente combinar las escalas municipales (análisis de las grandes tipologías y conglomerados de municipios) e inframunicipal (desagregación a nivel de sección censal y articulación interna).

\subsection{LOS MUNICIPIOS RESIDENCIALES}

Existen tres grandes grupos de municipios residenciales en función de su tamaño poblacional y el estatus socieconómico predominante entre su población residente: los municipios de elite, los residenciales de carácter suburbano y los residenciales mixtos o de clase media.

Los municipios de elite son municipios medios, entre 20 y 60 mil habitantes, que presentan concentraciones de grupos de nivel alto en torno al doble de la media de la Comunidad y que se encuentran muy próximos a la cabecera. Están formados por un núcleo urbano muy homogéneo donde se encuentran altas concentraciones de profesionales y técnicos; rodeado de secciones con viviendas más dispersas y baja densidad poblacional en la que la concentración de población de nivel alto también es abrumadora. Este subgrupo está compuesto por: Tres Cantos, Villaviciosa de Odón, Villanueva de la Cañada, Torrelodones, Las Rozas de Madrid, Majadahonda, Hoyo de 
Manzanares, Boadilla del Monte, Pozuelo de Alarcón y, al menos, la sección censal sur de Colmenar Viejo (ver figura 6).

Figura 6. Agrupación municipal y detalle inframunicipal zona noroeste

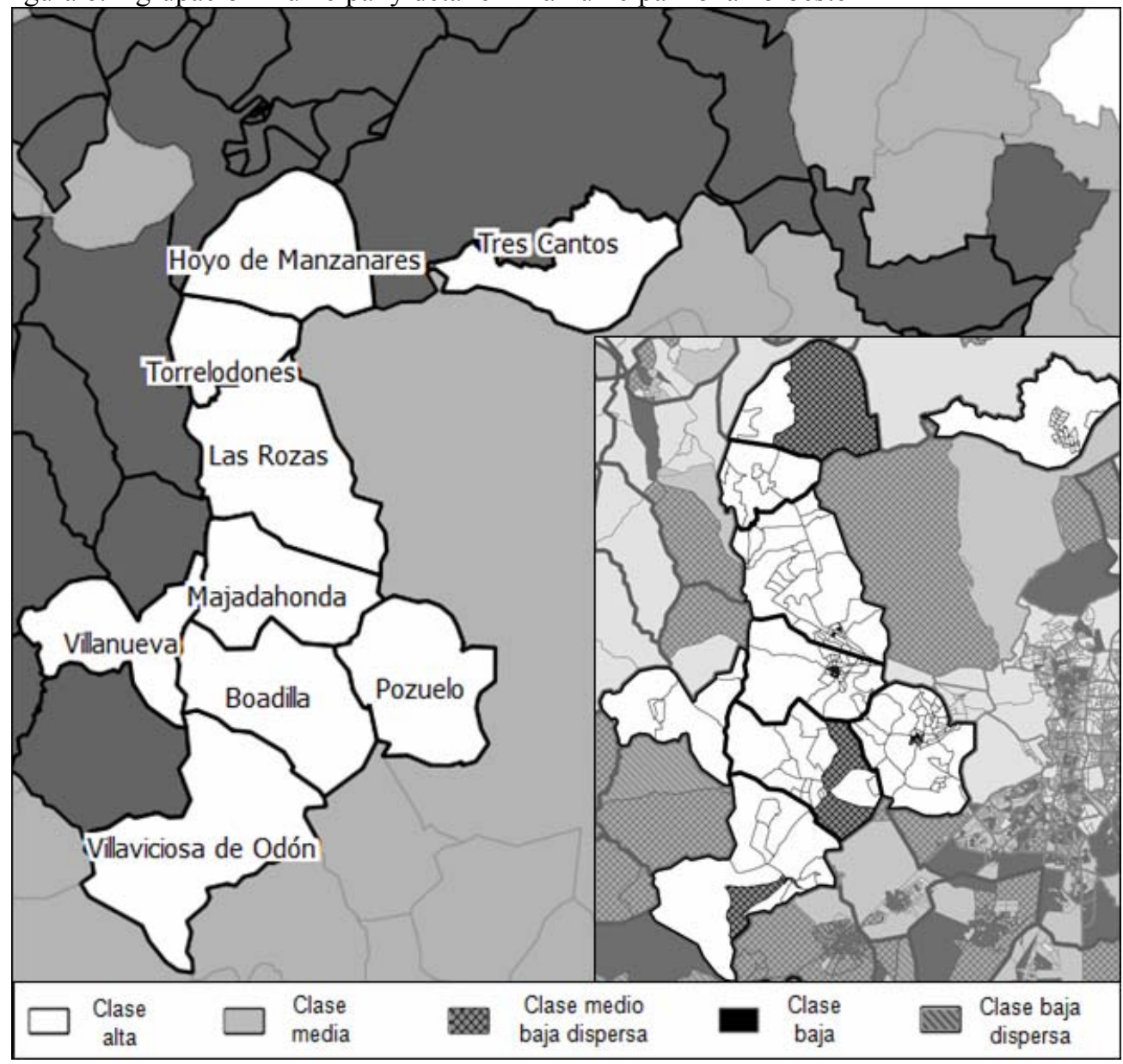

Fuente: INE, datos del Censo de 2001 e IECM, registros Seguridad Social de 2011 y elaboración propia.

Los municipios residenciales medios tienden a ser algo más pequeños que los de elite, en torno a 10.000 habitantes (excepto Collado Villalba que casi llega a los 50.000 ), y tienen concentraciones de niveles altos en torno a un $20 \%$ por encima de la media. Se localizan principalmente en la cuenca alta del Manzanares y en la del Jarama, zonas más alejadas de Madrid que los más próximos municipios de elite. Presentan centros más populares y periferias, generalmente de asentamiento residencial más acomodado (clase alta y media, aunque se dan secciones de carácter medio bajo disperso). 
Figura 7. Agrupación municipal y detalle inframunicipal zona sierra noroeste

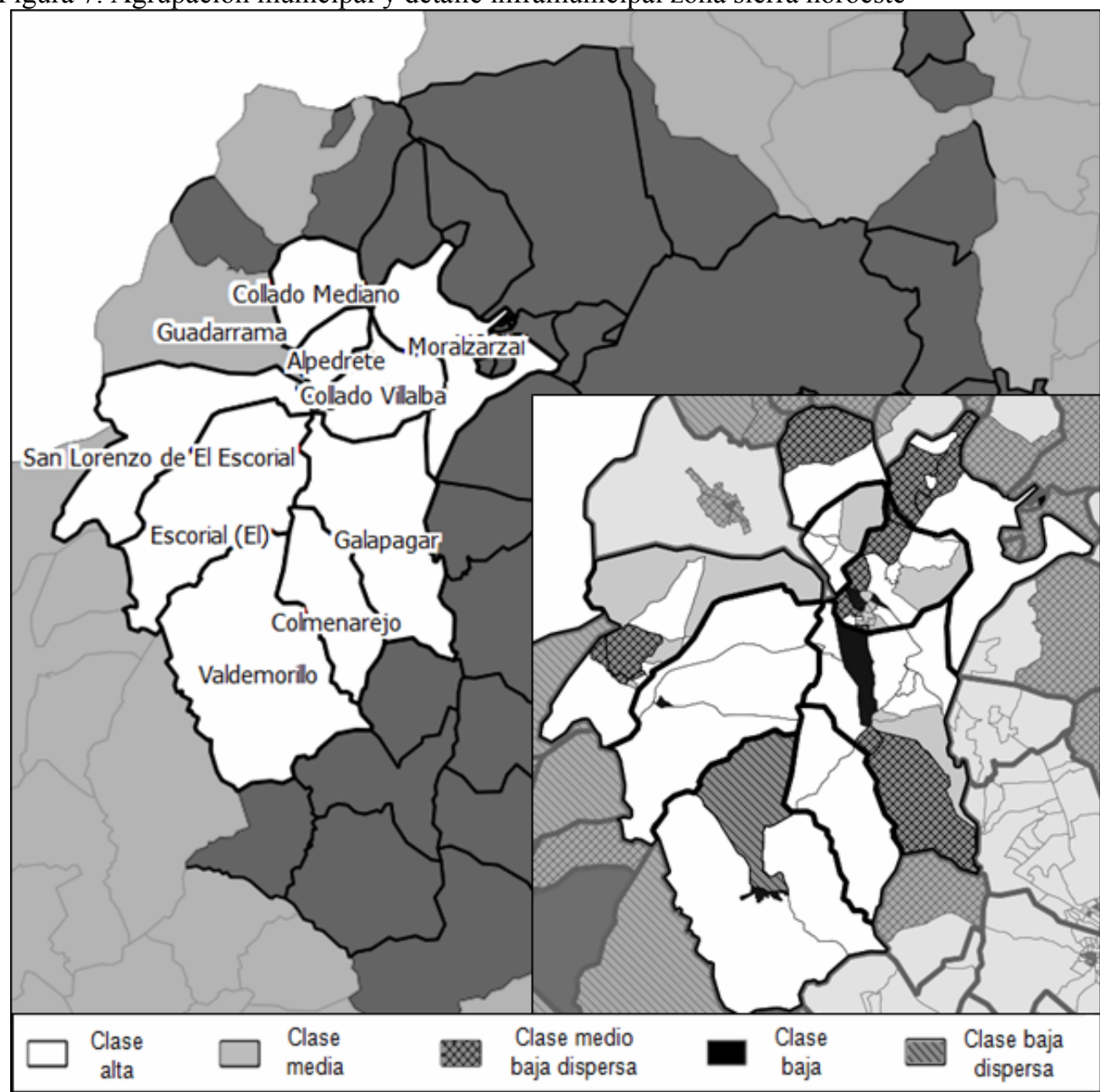

Fuente: Elaboración propia a partir de los datos del Censo de 2001 (INE) e IECM, registros Seguridad Social 2011.

Hay municipios en el límite espacial y social de la agrupación. Guadarrama se podría añadir, como Collado Villalba o San Lorenzo pero sus valores medios son algo más bajos. Además de este clúster, aparecen también otros municipios residenciales asociados a Alcalá y al corredor del Henares (municipios de Cobeña y Villalbilla - en concreto la urbanización cerrada Zulema-) y al grupo de municipios residenciales mixtos del Norte. 
Figura 8. Agrupación municipal y detalle inframunicipal zona norte

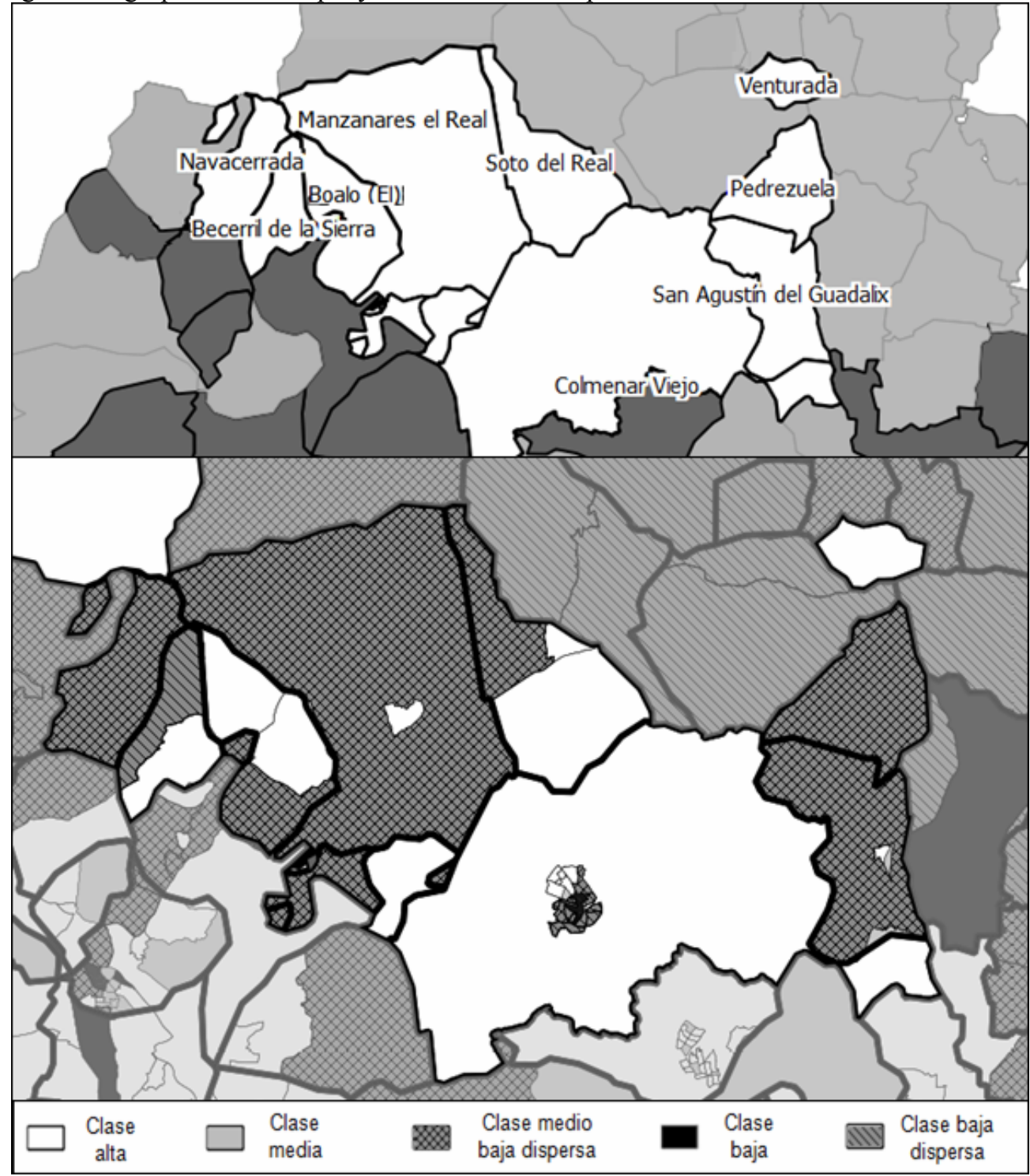

Fuente: INE, datos censo 2001 e IECM, registros Seguridad Social 2011 y elaboración propia.

La principal diferencia de municipios como Guadarrama, Collado Villalba o Valdemorillo respecto a la tipología media de los municipios residenciales, está marcada por la composición de su centro urbano, predominantemente popular (ver figura 7), en un contraste equivalente al caso de Colmenar Viejo para los municipios de elite (ver figura 8). Este patrón morfológico responde a municipios que no tienen una 
tradición elitista ni fuertes migraciones internas de población de clase alta hacia su núcleo urbano, pero que se localizan en un área de expansión residencial de clase alta por su proximidad a conexión a Madrid y su proximidad a los municipios de elite. Esto permite que sus términos municipales alberguen el desarrollo de urbanizaciones con estándares altos y la construcción de viviendas sueltas con condiciones y valores ambientales óptimos.

Los municipios mixtos o de clase media son generalmente pequeños, alrededor de los 5.000 habitantes, excepto Colmenar Viejo, de 35.000. Su concentración de clases altas se mantiene en la media de la región y se aglutinan principalmente en la zona norte, la cuenca alta del Manzanares. Su casuística y composición interna es más variada que la de los municipios de elite y residencial, produciendo frecuentes contrastes entre el carácter de clase de los núcleos urbanos y su periferia dispersa.

Este contraste es muy marcado en Colmenar Viejo, que tiene centros populares y periferias elitizadas. En San Agustín de Guadalix y Manzanares también se produce, pero de manera inversa: los núcleos más compactos concentran más las clases altas, mientras que sus periferias permiten mejores condiciones habitacionales a las clases medio bajas. También podrían considerarse municipios mixtos algunas zonas del núcleo poblacional conurbado de Alcobendas y San Sebastián de los Reyes (presentan perfiles con predominio de clases populares pero en sus secciones periféricas y poco densas se localizan clases altas).

\subsection{LOS MUNICIPIOS METROPOLITANOS}

Los municipios de metropolitanos están muy poblados y albergan grandes contingentes de población ocupada en categorías profesionales medias y bajas. Se pueden distinguir dos grandes agrupaciones socioespaciales: la agrupación de municipios obreros / trabajadores del sur y los municipios asociados a la dinámica del corredor del Henares. Entre ambos, el caso más atípico de Rivas, que presenta un perfil de clase medio alta.

El grupo de municipios de municipios con población trabajadora en categorías bajas es el grupo más poblado, especialmente enlos municipios más próximos de Móstoles, Alcorcón, Leganés, Getafe y Fuenlabrada y Parla entre los 150.000 y 200.000 habitantes. Humanes, Parla, Pinto, Valdemoro, Cienpozuelo y Aranjuez se encuentran en torno a los 30.000 habitantes y podrían conformar un subgrupo ya que no presentan núcleo dual y en ellos la clase medio baja dispersa tiene mucha importancia. 
Figura 9. Agrupación municipal y detalle inframunicipal zona Sur

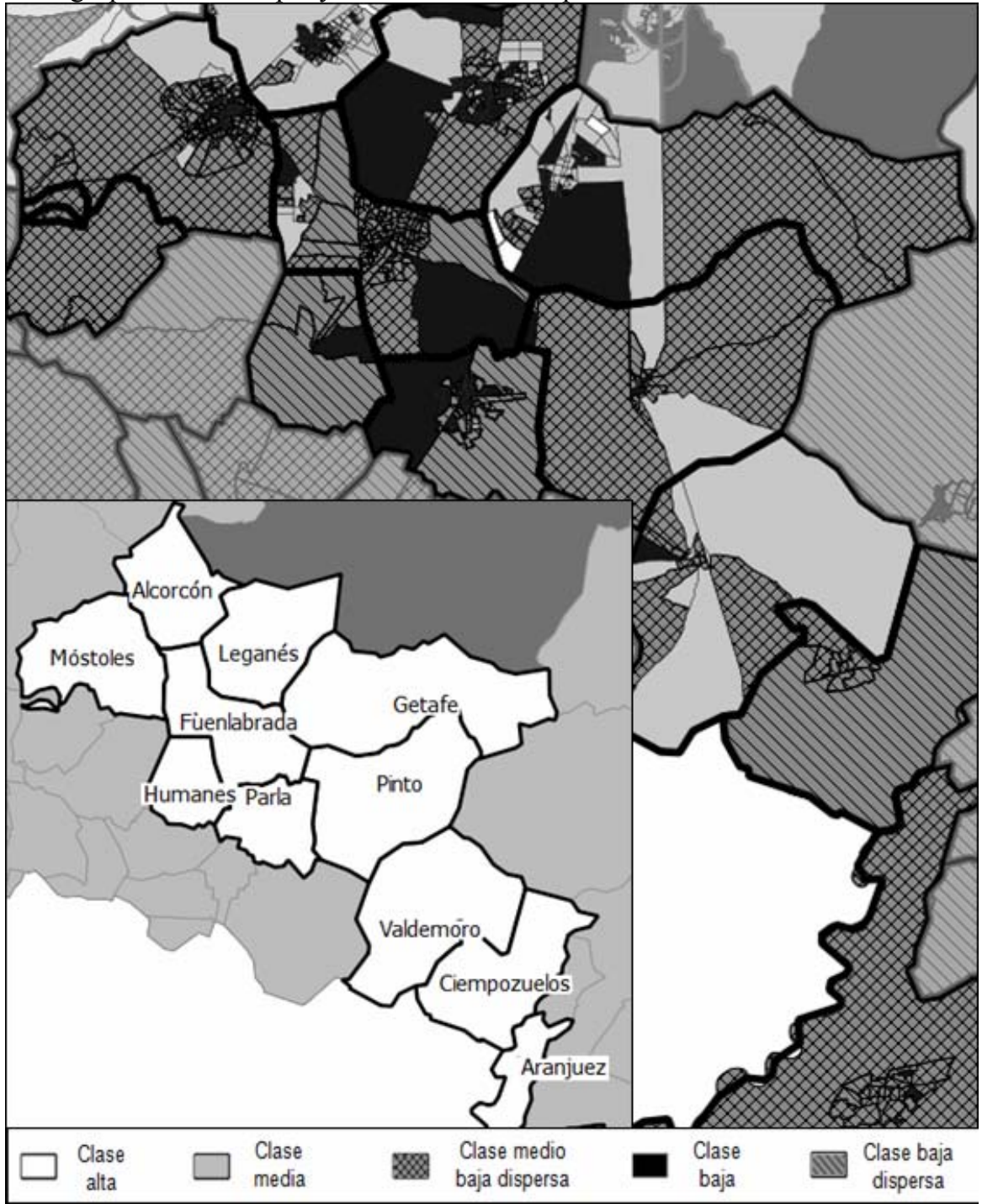

Fuente: INE, datos censo 2001 e IECM, registros Seguridad Social 2011 y elaboración propia.

Los municipios con población trabajadora/obrera, estructurados entorno a las vías A4 y A5, presentan núcleos centrales duales en los que, en al menos una mitad, se acumulan unas de las mayores aglomeraciones de trabajadores en ocupaciones sin cualificación, operarios y artesanos de toda la CAM. Es el caso del centro y el este de Móstoles; el oeste de Alcorcón; el centro y el sur de Leganés y el norte de Parla y Getafe. En las zonas del municipio que no están caracterizadas como de clase baja, predominan la clase medio baja dispersa, o la clase media, más presente en los muni- 
cipios limítrofes con Madrid. Excepcionalmente, también se encuentran algunas secciones de clase alta aislada. Este patrón morfológico responde a su proceso de crecimiento urbano a partir de los 60s. En Alcorcón y Getafe (Aguilera, 1988) y posiblemente también en Fuenlabrada y Leganés, se comenzaron a construir urbanizaciones con mejores calidades separadas del núcleo histórico. Posteriormente, los desarrollos urbanos continuaron la misma dinámica: construir viviendas con precios y calidades inferiores en torno al núcleo antiguo y superiores en torno del nuevo asentamiento residencial. Finalmente, ambos desarrollos se conurban dando lugar a núcleos urbanos duales. El estudio sobre la segregación residencial, el bajo rendimiento y el fracaso escolar en Alcorcón (Martín, 1999) acredita la relación entre residir en una zona con bajas características sociodemográficas y las bajas calificaciones, aunque resulta difícil establecer hasta qué punto la segregación y la concentración de las clases bajas multiplican las desventajas de de los estratos sociales más desfavorecidos, o sencillamente se encuentra asociada a la reducción de oportunidades derivadas de la propia pertenencia a una clase desfavorecida.

Figura 10. Agrupación municipal y detalle inframunicipal zona este

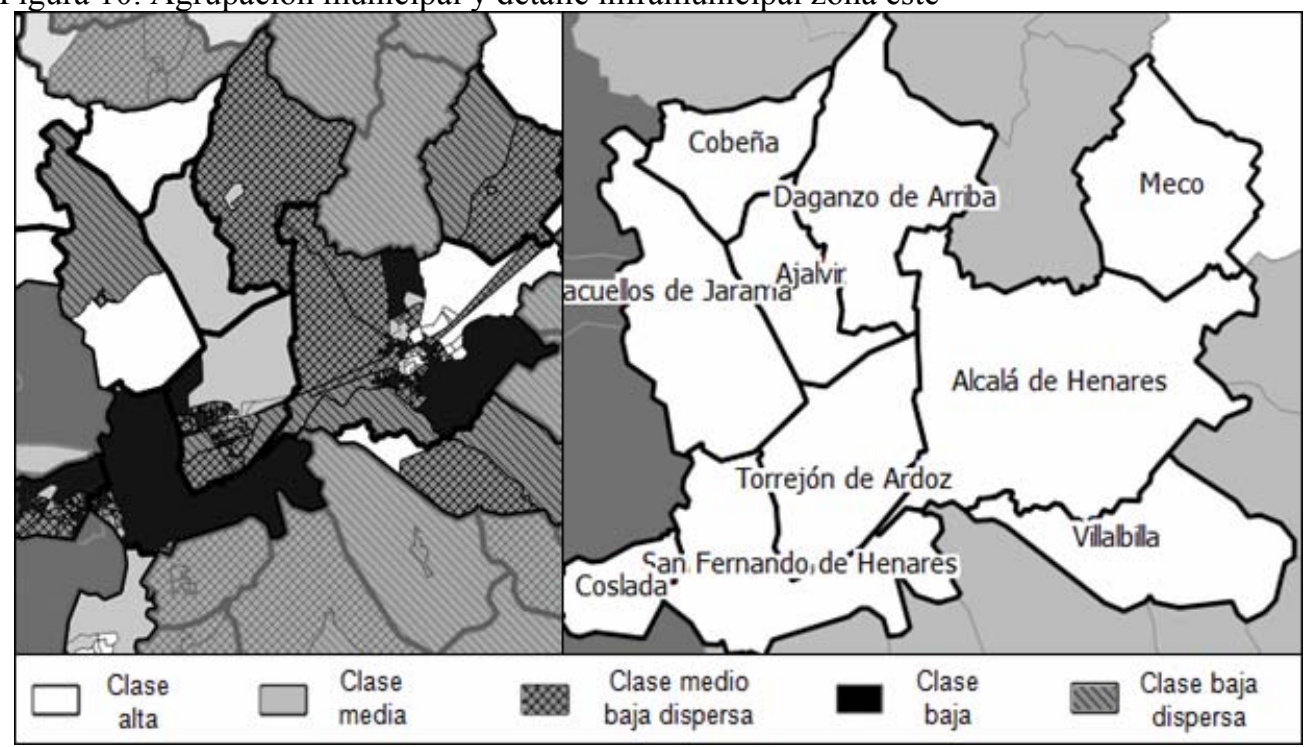

Fuente: Elaboración propia a partir del INE, datos del censo de 2001 e IECM, registros Seguridad Social 2011

El grupo de municipios asociados al corredor del Henares es la agrupación con una diversidad interna mayor, relacionada con que también sean el grupo que genera una dinámica funcional más propia, pivotando entre la cabecera de la región y el polo que generan Alcalá de Henares y el propio corredor. A Alcalá de Henares, San Fernando de Henares y Torrejón de Ardoz en el eje central, se le añaden Paracuellos de Jarama Aljavir, Daganzo de Arriba, Meco, Mejorada del Campo y Villalbilla. Se ha incluido 
Cobeña y, quizás se podrían haber incluído Ribas y Arganda, aunque ambos presentan valores y desarrollos atípicos: Ribas-Vaciamadrid con un perfil más residencial y Arganda, junto a San Martín de Valdeiglesias, son municipios difíciles de ubicar en este grupo o en el grupo de municipios obreros del sur.

Alcalá de Henares presenta varias secciones censales de clase alta (6) y media (5) en su centro urbano. Esto no ocurre con ningún otro municipio del sur o del este de Madrid. Tanto la diversidad social del conjunto de municipios, operarios y personal sin cualificación, o el centro elitizado de Alcalá están relacionados con la potencia de esta ciudad como subcentro en la Comunidad de Madrid. Alcalá, ya cuando comienzan las migraciones del campo a la ciudad que se producen durante de los años $60 \mathrm{~s}$ a los 80 s, era una ciudad consolidada que funciona como centro de servicios y empleo para una red comarcal de municipios (Díaz, 1986). En ella, las élites se habían situado en el centro administrativo de la ciudad, que no estaba degradado en los 70s y los desarrollos que alojaron a los emigrantes del campo se generaron alrededor de la ciudad existente. El patrón de composición social de Alcalá, infrecuente en la CAM, no es una excepción en las ciudades medias de la Región Metropolitana de Barcelona como Granollers, Terrasa o Sabadell (Rubiales, Bayona y Pujadas, en prensa). El mayor número de ciudades medias con centros elitizados y la relativa mayor polifuncionalidad en la RMB están relacionados, entre otros factores, con la existencia de un mayor número de ciudades que ya estaban consolidadas con cierta dinámica independiente de la cabecera regional en los años 60s y 70s.

El resto de municipios de este grupo presenta un contraste entre Coslada, San Fernando y Torrejón de Ardoz que tienen altos valores poblacionales y fuertes concentraciones de trabajadores sin cualificación, artesanos y operarios y el resto de municipios que, más pequeños, han ido funcionando como destino residencial para la suburbanización de clases medias y élites comarcales o del este de Madrid. Es el caso de Villalbilla, cuyos tres núcleos poblacionales dan cuenta de pueblo tradicional, de un desarrollo que ha recibido clases medias y de una urbanización cerrada en la zona más próxima a Alcalá, que tiene un carácter relativamente más exclusivo (y está vinculada a las clases altas de Alcalá).

\subsection{LA CIUDAD CENTRAL}

Un análisis pormenorizado de la distribución de las clases altas en el núcleo urbano de Madrid excede las posibilidades de este artículo. Existen numerosos análisis sobre la segregación étnica o en función de la nacionalidad de las poblaciones en el municipio de Madrid. La segregación según criterios socioeconómicos, de interés durante los 80s y 90s, se encuentra mucho menos actualizada entre otros, (Moreno, 1987 y 2003), (Leal, 1994 y 2004), (Observatorio Metropolitano, 2007), (Arranz, 1987 para La Latina). Aunque centrando su interés en los procesos de transformación. 
Figura 11. Detalle inframunicipal del municipio de Madrid

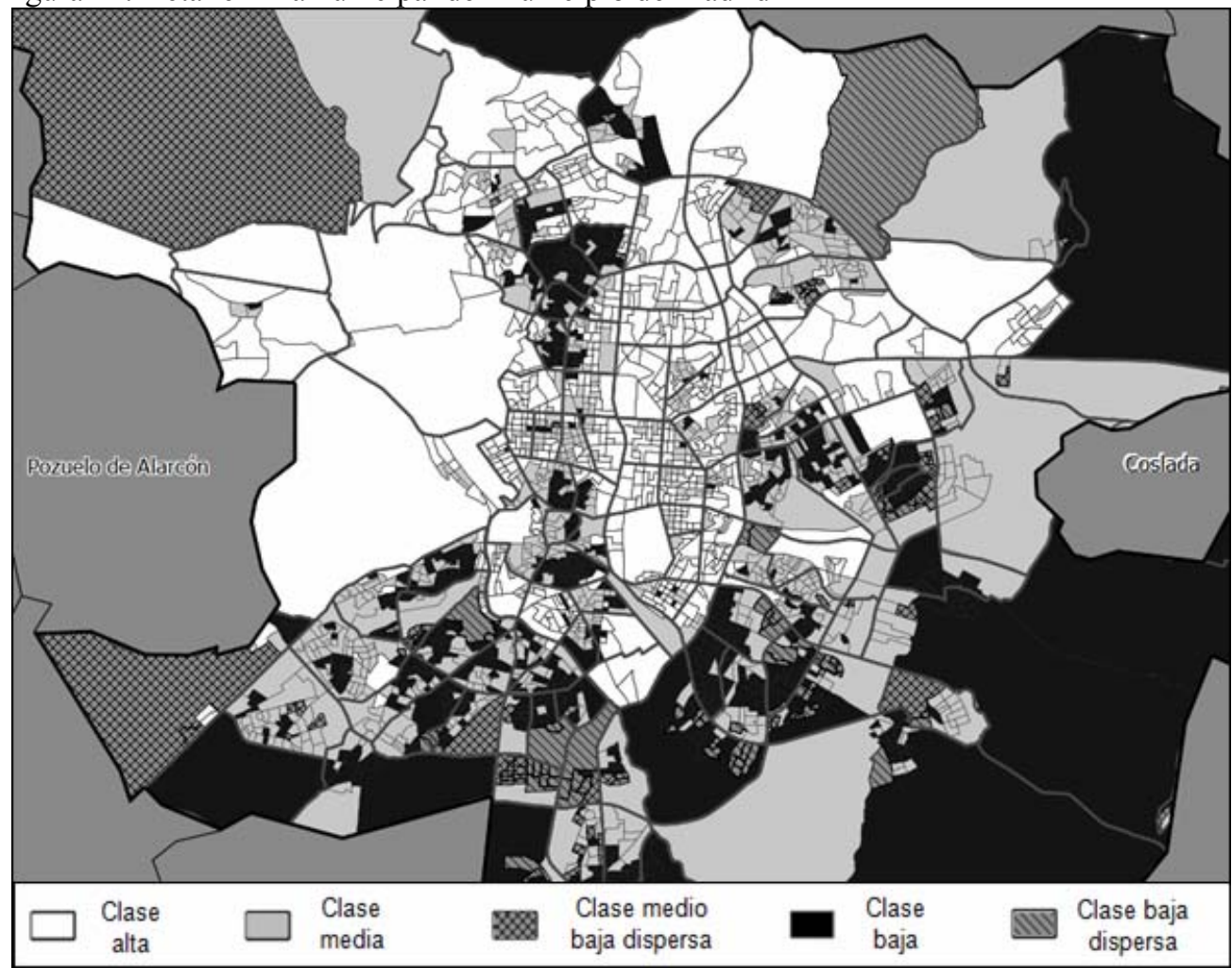

Fuente: INE, censo 2001 e IECM, registros seguridad social 2011 y elaboración propia.

Madrid es la ciudad cabecera de esta región, la capital del estado, un polo de referencia económica, dónde se localiza una gran parte de la población y de los puestos de trabajo de la Comunidad (ver figura 2). Es también el municipio con mayores contrastes sociales, con un eje central absolutamente elitizado (también respecto a sus actividades económicas y no solo residencialmente, García Escalona, 1992) que atraviesa un ensanche en el que predominan las clases altas, un núcleo histórico mixto con una composición clases medias y bajas similar a la que existe en la zona este: distritos de San Blas y zona sur del distrito Ciudad Lineal, que emparentan con Coslada y el corredor del Henares. Las mayores concentraciones de clases bajas se encuentran en la zona sur: distritos de La Latina, Carabanchel, Usera, Puente de Vallecas, Villaverde, Puente y Villa de Vallecas y Vicálvaro, en el distrito de Tetuán en el norte y los ya mencionados del centro y este. 


\section{ARTICULACIÓN FUNCIONAL INTERNA DE LOS MUNICIPIOS}

Como complemento al análisis de conglomerados municipales, se analiza la integración interna de estos conglomerados en base a la movilidad obligada. Aunque suele emplearse mayoritariamente en los análisis de geografía económica, de modelos de desarrollo, de localización de la actividades o para caracterizar el nivel de policentrismo o monocentrismo de las regiones metropolitanas (Gallo y Garrido, 2012; Méndez, 2011; o Río, 2009, entre otros), la movilidad obligada intermunicipal, estudiada mediante análisis de redes sociales, puede aplicarse en los trabajos sobre clases socio-espaciales, como complemento al análisis factorial y de conglomerados. La aportación de este tipo de análisis resultará más fructífera en tanto se acentúen las tendencias de las clases altas a distribuirse en una escala mayor, saliendo de la Madrid hacia municipios metropolitanos. Por otra parte, el cuestionamiento la de contigüidad como variable relevante para los análisis de la nueva ciudad-red (Castells, 2004) obliga a examinar el nivel empírico de integración funcional de los conglomerados propuestos y de las clases socioespaciales, porque la suposición de que dos municipios contiguos y con perfiles poblacionales similares se encuentran relacionados ya no puede realizarse de manera automática.

La figura 12 representa la red de desplazamientos entre municipios en función del porcentaje de trabajadores que se mueven de uno a otro para aquellos desplazamientos pertenecientes a la CAM, mayores del $0,5 \%$, desde y hacia municipios de más de 2.000 habitantes. Aparecen en tonos más oscuros los municipios y los flujos de trabajadores en categorías más bajas y en tonos más claros los de las altas. Municipios más relacionados aparecen más próximos y municipios menos relacionados, más alejados. Para poder visualizar los subcentros y agrupaciones dentro de la CAM, también se ha excluido Madrid, cuyo gran peso tiende a ocultar las demás interacciones. Este tipo de algoritmos (gravitacionales o dirigidos por fuerzas) son los mejores para representar interrelaciones espaciales ya que sitúan cada nodo en función de su relación con todos los demás y no tanto según sus características propias.

Lo primero que se debe destacar del análisis de redes es que, a partir de los datos de movilidad obligada, los nodos del sistema reconstruyen la propia configuración espacial de la CAM, localizándose de manera equivalente a sus respectivas ubicaciones geográficas, lo que permite reconocer rápidamente las agrupaciones de municipios generadas. A grandes rasgos, reproducen las agrupaciones municipales generadas en el análisis a nivel municipal (ver figura 12).Una mayor precisión de la visualización permitiría afinar más en la configuración de subgrupos. Aún así, esta primera, permite desambiguar casos menos claros para el análisis de conglomerados socioespaciales. En primer lugar, Rivas Vaciamadrid se encuentra próxima pero mantiene una dinámica independiente tanto del conglomerado de Alcalá como del conglomerado del sur. A pesar de la proximidad y parecido socioeconómico, Arganda no se encuentra vinculada a los municipios del sur, sino a la propia Rivas. En segundo lugar, se aprecian tres subgrupos en la gran agrupación de municipios del sur, que coinciden con los subcentros propuestos por Gallo y Rivera (2010): por un lado los próximos a Alcorcón, Villaviciosa, Móstoles... (con un carácter medio) por otro Leganés, Fuen- 
labrada, Getafe, Parla... (con más ocupados como operarios y peones) y un último eje con los próximos a Pinto, Valdemoro, Aranjuez... Finalmente, las dos agrupaciones de municipios del noroeste también podrían integrarse junto a Tres Cantos y Colmenar Viejo en una gran zona de clase alta.

Figura 12. Flujos de movilidad obligada en la CAM, 2011

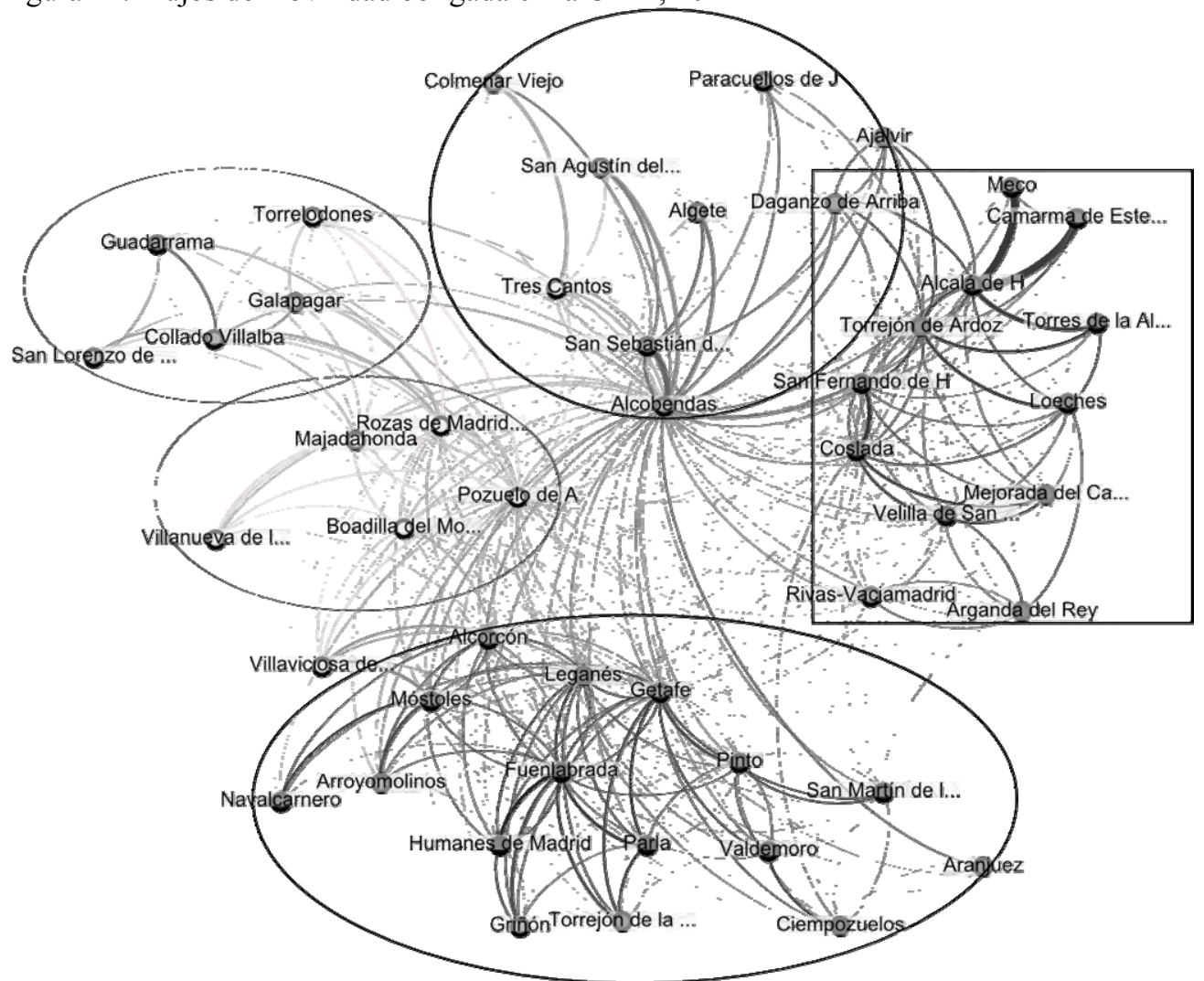

Red de desplazamientos entre municipios en función del porcentaje de trabajadores que se mueven de uno a otro para aquellos desplazamientos pertenecientes a la CAM, mayores del 0,5\%, desde y hacia municipios de más de 2.000 trabajadores inscritos en la seguridad social 2011. Municipios y desplazamientos de grupos de cotización bajos, en tonos más oscuros. Mayores densidades de flujos en tonos más oscuros.

Fuente: IECM, registros en la seguridad social, 2011. Elaboración propia, algoritmo ForceAtlas2, programa Gephi. 


\section{CONCLUSIONES}

El análisis de la configuración de las clases socioespaciales en la Comunidad Autónoma de Madrid muestra un territorio con una articulación jerárquica y estable, en el que se produce una segregación espacial importante, continuos procesos de desconcentración que van reduciendo la predominancia total de Madrid, así como configuraciones de especialización socioeconómica entre grupos de municipios de la región metropolitana.

Las clases altas en la Comunidad de Madrid se distribuyen en torno a dos grandes patrones: congregación en los centros urbanos y seclusión en secciones dispersas y municipios de la CAM. Este grupo de municipios especializados en los grupos socioeconómicos altos, se ubica muy próximo a Madrid y mantiene una estrecha vinculación interna (no tan evidente en el grafo de redes de la figura 12 ya que se puede una baja interacción con los tonos claros en los que se representa la -intensa- movilidad obligada entre municipios con ocupaciones de categoría alta).

Los cinco grandes grupos son los municipios de elite, los residenciales medios (que se encuentran próximos y conectados), los de la zona norte, los de la zona sur (que pueden dividirse en los subgrupos de Alcorcón y Móstoles; Fuenlabrada y Parla; y Pinto y Valdemoro) y los del corredor del Henares (a los que Rivas y Arganda podrían vincularse). Estas agrupaciones, además de su contigüidad espacial y similitud socioeconómica, mantienen más estrechas relaciones funcionales de interconexión en base a los flujos residencia-trabajo.

A nivel inframunicipal, se observan unos niveles importantes de segregación, especialmente en los grupos con perfiles socioeconómicos más altos y más bajos. Las clases altas en la CAM se segregan mediante dos estrategias básicas: congregación en centros urbanos y retirada (seclusión) en zonas dispersas y municipios especializados del área metropolitana, con un patrón similar al observado en la Región Metropolitana de Barcelona (Rubiales et al. en prensa). Fruto del tradicional monocentrismo de la CAM y de la importancia de las migraciones en el crecimiento demográfico de la región, se observa una gran abundancia de centros municipales densos en los que se concentran los niveles socioeconómicos menos favorecidos de la escala social. Son municipios que crecieron fuertemente durante los años sesenta y setenta. Si, posteriormente, se encontraban en la zona oeste o norte, fueron recibiendo población con perfiles más acomodados durante los últimos decenios. Alcalá de Henares es el caso inverso. Alcalá es el municipio de referencia en el subcentro más importante de toda la provincia de Madrid (actual e históricamente). Su ubicación geográfica y su especialización industrial y logística hacen que tenga una zona muy elitizada en su centro y secciones más populares alrededor.

A nivel municipal, resulta notable que los grandes cambios poblacionales y el crecimiento poblacional experimentado por la región no han alterado la jerarquización socioeconómica de los municipios, que se presenta muy estable. En todo caso, parece que la articulación socioespacial de las clases en la CAM ha rebasado definitivamente el límite municipal de la ciudad central y se consolida a niveles y escalas cada vez mayores. 


\section{BIBLIOGRAFÍA}

ATKINSON, R. y FLINT, J. (2004) Fortress UK? Gated communities, the spatial revolt of the elites and time-space trajectories of segregation. En: Housing Studies. Vol. 19, no.6, pp.875-892.

AGUILERA ARILLA, M. J. (1988) El modelo de crecimiento de Alcorcón. En: Anales de Geografia, pp. 121-137.

ARRANZ LOZANO, M. (1987) Evolución del proceso de producción de espacio urbano en el distrito de La Latina:(1974-1984). En: Anales de geografía de la Universidad Complutense. pp. 379-388.

BOURDIEU, P. (1988) La distinción: criterio y bases sociales del gusto. Madrid: Taurus Ediciones,

BOURDIEU, P. (2001) Las estructuras sociales de la economía. Argentina: Manantial.

CASTELLS, M. (2004) La era de la información: economía, sociedad y cultura. Siglo XXI.

DÍAZ MUÑOZ, M. Á. (1986) Alcalá de Henares: la diferenciación residencial en una ciudad histórica del área metropolitana de Madrid. In: Anales de geografia de la Universidad Complutense. pp.253-272.

FRUCHTERMAN, T. M. J. y REINGOLD, E. M. (1991) Graph drawing by forcedirected placement. En: Software: Practice and experience. Vol. 21, $\mathrm{n}^{\mathrm{o}}$. 11, pp. $1129-1164$.

GALLO RIVERA, M.T. y GARRIDO YSERTE, R. (2012) Una aproximación a la estructura urbana policéntrica en la Comunidad de Madrid. UPC.

GARCÍA ESCALONA, E. (1992) El eje centro de Madrid. In: Anales de geografía de la Universidad Complutense.. pp. 313-324.

GARCÍA HERRERA, L.M. (2007) Elitización: propuesta en español para el término gentrification. En: Biblio 3w: revista bibliográfica de geografía y ciencias sociales, Vol.6. Disponible en:

http://www.raco.cat/index.php/biblio3w/article/viewArticle/66372/0.

GARCÍA PALOMARES, J. C. (2008) Incidencia de las características sociodemográficas en la movilidad metropolitana: El caso de Madrid. En: Anales de Geografía de la Universidad Complutense. pp.53-83.

GRAHAM, S. y MARVIN, S. (2001) Splintering urbanism: networked infrastructures, technological mobilities and the urban condition. Londres: Routledge,.

HARVEY, D. (2008) El derecho a la ciudad. En: New left review, Vol. 53. Disponible en:

http://www.moviments.net/espaimarx/docs/6786f3c62fbf9021694f6e51cc07fe3c.pdf.

HORTAS-RICO, M. y SOLÉ-OLLÉ, A. (2010) Does urban sprawl increase the costs of providing local public services? Evidence from Spanish municipalities. En: Urban Studies., Vol. 47, no. 7, pp. 1513-1540.

INE. (2007) Evaluación del la calidad de los datos del Censo de Población 2001. 
JACOMY, M., HEYMANN, S., VENTURINI, T. y BASTIAN, M.. (2011) ForceAtlas2, A Graph Layout Algorithm for Handy Network Visualization. Disponible en: http://webatlas.fr/tempshare/ForceAtlas2_Paper.pdf.

LEAL, J. 1994 Cambio social y desigualdad espacial en el área metropolitana de Madrid (1986-1991). En: Economía y Sociedad., Vol. 10, pp. 61-81.

LEAL, J. (2004) Segregation and social change in Madrid metropolitan region. En: The Greek Review of Social Research., Vol. 113, nº. A, pp. 81-104.

LEES, L. (2011) The geography of gentrification: Thinking through comparative urbanism. En: Progress in Human Geography.

MALHEIROS, J. (2002) Ethni-cities: residential patterns in the Northern European and Mediterranean metropolises-implications for policy design. En: International Journal of Population Geography., Vol. 8, nº. 2, pp. 107-134.

MARCUSE, P. (1997) The ghetto of exclusion and the fortified enclave. En: American Behavioral Scientist., Vol. 41, no. 3, pp. 311-326.

MARTÍN JIMÉNEZ, (1999) A. Fracaso escolar en las enseñanzas medias de Alcorcón. En: Anales de geografia de la Universidad Complutense. pp. 325-348.

MÉNDEZ GUTIÉRREZ DEL VALLE, R. y TÉBAR ARJONA, J. (2011) El mapa de la economía del conocimiento en la región metropolitana de Madrid. En: Anales de geografia de la Universidad Complutense. pp. 139-161.

MORENO JIMÉNEZ, A. (1987) La diferenciación social del espacio en Carabanchel. En: Anales de geografia de la Universidad Complutense. pp. 471-479.

MORENO, A, FERNÁNDEZ, F, VÁZQUEZ, C y PRIETO, M.E. (2003) La distribución espacial de la renta en la Comunidad de Madrid: análisis y aplicaciones. Instituto de Estadística de la Comunidad de Madrid.

OBSERVATORIO METROPOLITANO. (2007) Madrid: ¿La suma de todos? Globalización, territorio, desigualdad. En: Energía., Vol. 18, pp. 19-300.

PUJADAS, I. y GARCÍA, A. (2005) Movilización residencial y polarización social: La diferenciación social de los nuevos espacios residenciales en la Región Metropolitana de Barcelona. En: AGE, Espacios públicos, espacios privados. Un debate sobre el territorio. Santander: XIX Congreso de Geógrafos Españoles.

RÍO LAFUENTE, I. RODRÍGUEZ, J. (2009) Áreas metropolitanas en transformación. Presente y futuro del Corredor del Henares en el área funcional madrileña. En: Anales de Geografía de la Universidad Complutense. pp. 139-165.

RUBIALES, M., BAYONA, J., PUJADAS, I. (en prensa) Patrones espaciales de la segregación residencial en la región metropolitana de Barcelona: pautas de segregación voluntaria de los grupos altos. En: Scripta Nova, revista electrónica de geografia y ciencias sociales

SOJA, E.W. (2000) Postmetropolis: critical studies of cities and regions. WileyBlackwell,

VAN AMERSFOORT, H., DE KLERK, L., GLEBE, G. y O'LOUGH, J. (1987) Dynamics of Immigrant Settlement: Surinamese, Turks and Maroccans in Amsterdam 1973-1983: Franz Steiner Verlag.

WACQUANT, L. J.D. (2007) Los condenados de la ciudad: Gueto, periferias y Estado. Siglo veintiuno editores. 
Anexo 1: Variables y agrupaciones empleadas

\begin{tabular}{|c|c|}
\hline Variable del censo & Agrupación operativa \\
\hline Población Extranjera & $\%$ Población extranjera \\
\hline 1 - Dirección de las empresas y de las administraciones públicas & \multirow{2}{*}{ \% Población con Ocupaciones altas } \\
\hline 2 - Técnicos y profesionales científicos e intelectuales & \\
\hline 3 - Técnicos y profesionales de apoyo & \multirow{2}{*}{$\begin{array}{l}\% \text { Población con Ocupaciones medio } \\
\text { altas }\end{array}$} \\
\hline 4 - Empleados de tipo administrativo & \\
\hline $\begin{array}{l}5 \text { - Trabajadores de los servicios de restauración, personales, } \\
\text { protección y vendedores de los comercios }\end{array}$ & \multirow{5}{*}{$\begin{array}{c}\% \text { Población con Ocupaciones medio } \\
\text { bajas }\end{array}$} \\
\hline 6 - Trabajadores cualificados en la agricultura y en la pesca & \\
\hline $\begin{array}{l}7 \text { - Artesanos y trabajadores cualificados de las industrias } \\
\text { manufactureras, la construcción, y la minería, excepto los } \\
\text { operadores de instalaciones y maquinaria }\end{array}$ & \\
\hline 8 - Operadores de instalaciones y maquinaria, y montadores & \\
\hline 0 - Fuerzas armadas & \\
\hline 9 - Trabajadores no cualificados & \% Población con ocupaciones bajas \\
\hline No sabe leer ni escribir & \multirow{2}{*}{ Grado 0} \\
\hline Primaria incompleta & \\
\hline 1er Grado & \multirow{3}{*}{ \% Población grado 1} \\
\hline ESO, EGB, Bachillerato & \\
\hline FP 1er grado & \\
\hline FP $2^{\circ}$ Grado & \multirow{2}{*}{ \% Población grado 2} \\
\hline Bachillerato Superior & \\
\hline Diplomatura & \multirow{2}{*}{ \% Población grado 3} \\
\hline Licenciatura y Doctorado & \\
\hline Empresario o profesional que emplea personal & \multirow{2}{*}{ \% Población empresaria } \\
\hline Empresario o profesional que no emplea personal & \\
\hline Otra situación (ayuda familiar) & \multirow{2}{*}{ \% Población pequeño propietaria } \\
\hline Otra situación (miembro de cooperativas) & \\
\hline Trabajador por cuenta ajena con carácter fijo o indefinido & \multirow{2}{*}{ \% Población trabajadora } \\
\hline Trabajador por cuenta ajena con carácter eventual, temporal... & \\
\hline$\%$ de viviendas de - de 70 metros cuadrados & $\%$ de viviendas de - de $70 \mathrm{~m} \ldots$ \\
\hline$\%$ de viviendas entre 70 y 120 metros cuadrados & $\%$ de viviendas entre 70 y $120 \mathrm{~m} .$. \\
\hline$\%$ de viviendas de + de 120 metros cuadrados & $\%$ de viviendas de + de $120 \mathrm{~m} \ldots$ \\
\hline
\end{tabular}

Fuente: Elaboración propia. 
Anexo 2: Valores medios de los conglomerados resultantes del análisis multifactorial

\begin{tabular}{|l|r|r|r|r|r|}
\hline & $\begin{array}{c}\text { Clase } \\
\text { alta }\end{array}$ & $\begin{array}{c}\text { Clase } \\
\text { media }\end{array}$ & $\begin{array}{c}\text { Clase } \\
\text { medio baja } \\
\text { dispersa }\end{array}$ & $\begin{array}{c}\text { Clase } \\
\text { baja }\end{array}$ & \multicolumn{1}{c|}{$\begin{array}{c}\text { Clase baja } \\
\text { dispersa }\end{array}$} \\
\hline Leyenda en los mapas & & & & & \\
\cline { 1 - 3 } Número de secciones censales & 867 & 1019 & 496 & 1162 & 362 \\
\hline \% alta ocupación & 49,1 & 25,6 & 16,7 & 13,3 & 10,2 \\
\hline \% medio alta ocupación & 27,3 & 32,1 & 26,6 & 24,1 & 18,5 \\
\hline \% medio baja ocupación & 15,9 & 31,2 & 44,5 & 45,0 & 55,2 \\
\hline \% baja ocupación & 6,7 & 10,3 & 11,1 & 17,0 & 15,5 \\
\hline \% grado 0 & 1,7 & 3,0 & 4,3 & 7,1 & 8,3 \\
\hline \% grado 1 & 4,5 & 9,5 & 14,0 & 16,5 & 21,3 \\
\hline \% grado 2 & 37,4 & 56,4 & 63,8 & 59,9 & 61,1 \\
\hline \% grado 3 & 56,5 & 31,1 & 17,8 & 16,5 & 9,3 \\
\hline \% viviendas menos 75 m & 22,3 & 53,1 & 24,1 & 78,0 & 26,8 \\
\hline \% viviendas de 75 a 120 & 44,9 & 42,5 & 65,5 & 20,4 & 63,6 \\
\hline \% de viviendas mas 120 & 32,7 & 4,4 & 10,5 & 1,6 & 9,6 \\
\hline \% empresarios con trabajadores & 7,7 & 4,1 & 5,1 & 3,2 & 5,0 \\
\hline \% empresarios sin trabajadores & 8,4 & 7,2 & 7,7 & 7,1 & 9,0 \\
\hline \% trabajadores & 83,9 & 88,7 & 87,1 & 89,7 & 86,0 \\
\hline \% población extranjera & 5,2 & 6,6 & 4,2 & 10,6 & 4,3 \\
\hline \% parados & 8,5 & 11,2 & 11,9 & 13,3 & 14,1 \\
\hline
\end{tabular}

Fuente: INE, censo 2001. Elaboración propia. 